\title{
Indicator value of lotic water mites (Acari: Hydrachnidia) and their use in macroinvertebrate-based indices for water quality assessment purposes
}

\author{
F.P. Miccoli ${ }^{(1)}$, P. Lombardo $o^{(1,2), \star}$, B. Cicolani $i^{(1)}$
}

Received April 7, 2013

Revised July 15, 2013

Accepted August 20, 2013

Key-words: water mites, biotic indices, water quality

\section{ABSTRACT}

The Water Framework Directive (WFD) of the European Union includes benthic macroinvertebrates for the ecological assessment of running waters. The invertebrate-based Star-ICMi index, adopted in 2010, does not include Hydrachnidia (water mites) in its complex formulation. However, Hydrachnidia are associated with many environmental variables and may be useful for stream ecological characterization. We have therefore assessed the bioindicator value of Hydrachnidia in streams of central Italy, and the ability of two mite-containing (the PTH and the newly formulated $\mathrm{PTH}_{\text {fam }}$ indices) and four mite-excluding biotic indices (Star-ICMi, BMWP, ASPT, and IBE) to characterize 216 sites ranging from semipristine to impacted. Mite bioindicator value was high at family level. Index reliability was consistently low for the PTH and ASPT indices. Distribution of mite families across quality classes (QCs) was fully separated only for the $\mathrm{PTH}_{\mathrm{fam}}$ index. QC assignment remained reliable at high index values (i.e., at high ecological status) for the $\mathrm{PTH}_{\text {fam }}$ and BMWP indices, while logarithmic correlations between the $\mathrm{PTH}_{\mathrm{fam}}$ and the other indices suggest that the latter may misrepresent sites in high, good, and moderate ecological status sensu WFD. Further studies on the PTH $\mathrm{H}_{\text {fam }}$ index are warranted in light of its simplicity, high reliability, and low sampling and taxonomic identification effort.

\section{RÉSUMÉ}

Valeur d'indicateur des acariens d'eau courante (Acari : Hydrachnidia) et leur utilisation dans les indices macro-invertébrés pour l'évaluation de la qualité de l'eau

Mots-clés : acariens aquatiques, indices biotiques, qualité de l'eau
La Directive Cadre sur l'Eau (DCE) de l'Union européenne comprend les macroinvertébrés benthiques pour l'évaluation écologique des eaux courantes. L'indice invertébré Star-ICMi, adopté en 2010, ne comprend pas les Hydrachnidia (hydracariens) dans sa formulation complexe. Cependant, les Hydrachnidia sont associés à de nombreuses variables environnementales et peuvent être utiles pour la caractérisation écologique des cours d'eau. Nous avons donc évalué la valeur de bioindicateurs des Hydrachnidia dans les ruisseaux du centre de l'Italie, et la capacité des deux indices prenant en compte les acariens (les indices PTH et PTH $\mathrm{fam}_{\mathrm{fam}}$ nouvellement formulé) et de quatre indices biotiques ne prenant pas en compte les acariens (Star-ICMi, BMWP, ASPT, et BIE) pour caractériser 216 sites allant de

(1) Department of Civil, Architectural and Environmental Engineering (DICEAA) - M. Giustini Ecology Lab; Coppito Science Center; University of L'Aquila; via Vetoio 20 - Coppito; 67100 L'Aquila, Italy

(2) Limno Consulting; via Bedollo 303, 00124 Rome, Italy

^ Corresponding author: p.lombardo@limnoconsulting.com; physa@tiscali.it 
semipristine à pollués. La valeur bioindicatrice des hydracariens est élevée au niveau de la famille. La fiabilité de l'indice était toujours faible pour les indices PTH et ASPT. La répartition des familles d'acariens dans toutes les classes de qualité (QCs) a été entièrement réalisée seulement pour l'indice $\mathrm{PTH}_{\text {fam. }}$. L'affectation QC est restée fiable à des valeurs d'indice élevé (c'est-à-dire, très bon état écologique) pour les indices de $\mathrm{PTH}_{\text {fam }}$ et BMWP, tandis que les corrélations logarithmiques entre le $\mathrm{PTH}_{\mathrm{fam}}$ et les autres indices donnent à penser que celui-ci peut mal estimer les sites en très bon, bon et état écologique modéré sensu DCE. D'autres études sur l'indice $\mathrm{PTH}_{\mathrm{fam}}$ sont justifiées en raison de sa simplicité, sa grande fiabilité et d'un faible effort d'échantillonnage et d'identification taxonomique.

\section{INTRODUCTION}

The economical and technological development of the European Union (EU) has led to increased stress and deterioration on Europe's aquatic ecosystems. Ever-increasing water use and pollution, human modifications of watercourse hydrography, removal of riparian vegetation, and human-driven changes in land use have brought about the loss of aquatic biodiversity (Allan and Flecker, 1993; Allan, 2004; Suriano et al., 2011).

The identification of reliable indicators of environmental quality is a key theme in applied ecological research. Limnologists are developing monitoring strategies based on biological indicators and indices that synthetically express ecosystem structure and functioning, while separating human-derived impacts from natural variability. One of the main difficulties encountered in developing environmental indices is the selection of appropriate indicators that reflect ecosystem complexity in the simplest, most synthetic terms.

The EU's Water Framework Directive (WFD), an all-encompassing program for monitoring, evaluating, and improving the ecological status of Europe's aquatic ecosystems, bases its definition of ecological status on ecological research. The basic principle of the WFD is that water resources need to fulfill as many environmental functions as possible without sacrificing their long-term sustainability and accessibility. The WFD has therefore abandoned the old-fashioned concept of ecosystem protection through the establishment of isolated nature reserves specifically targeting faunal and floristic conservation. Instead, the WFD's scope is the protection and improvement of the ecological status of all aquatic ecosystems from deterioration, thus promoting a long-term sustainable use of water resources (EU, 2000).

While the main goal of the WFD remains EU-wide, the development and (inter)calibration of the necessary monitoring and evaluation methods have been delegated to the individual Member States (MSs), whose initial task was the identification of the biological parameters that best describe the ecological status of surface waters. For running waters, such biological parameters include macrophytes, benthic diatoms, fish, and benthic macroinvertebrates (Johnson et al., 2006). Each parameter is described by a numerical index expressed as the ratio between the observed ecological quality and a reference condition, defined as the ecological status expected in the absence (or with the lowest degree) of human disturbance. The numerical values of all such indices are therefore expressed as Ecological Quality Ratios, or EQRs (Buffagni et al., 2005) (Figure 1).

Reference sites have been or are being identified and EQR metrics have been (are being) calculated for each biological parameter, for each ecosystem type and for each hydroecoregion (Buffagni et al., 2007). The STAR-ICMi index has been adopted eventually for stream assessments based on benthic macroinvertebrates (Buffagni and Furse, 2006). Benthic macroinvertebrates are widely used in biotic indices (e.g. Dallas, 2012).

The observation of the close relationship between water mite ecology and environmental conditions and the consequent argument for water mites as environmental bioindicators date back to the early $20^{\text {th }}$ century (Walter, 1924; Viets, 1936). Such early arguments are supported by more recent observations in lotic and lentic systems (Schwoerbel, 1964; Biesiadka 


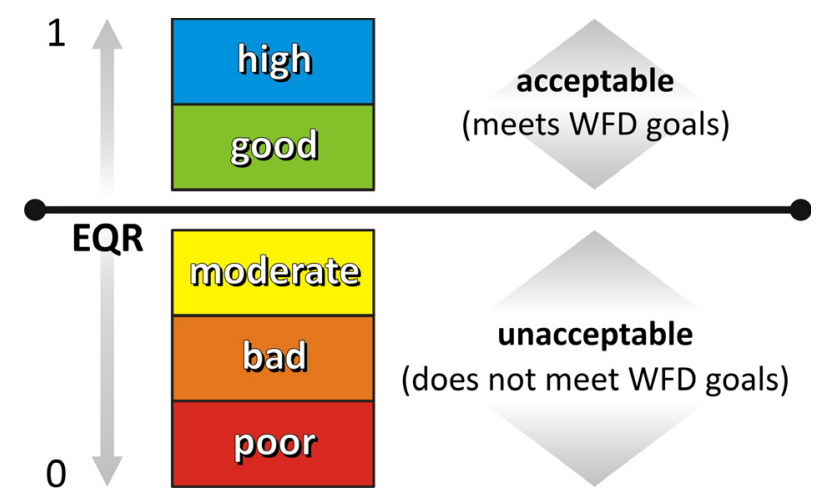

\section{Figure 1}

The five quality classes (QCS) defined by the Water Framework Directive (WFD) on the basis of the ecological quality ratio (EQR), for Europe's aquatic ecosystems. EQRs are defined for each area and ecosystem type on the basis of the least impacted localities in the area. High-quality sites are those for which $E Q R \approx 1$, i.e., for which the observed conditions depart only little from reference conditions. According to the WFD, ecological status is acceptable for sites classifed in "high" or "good" ecological status (QCs I and II, respectively), while sites in "poor" to "moderate" status (QCs III-V) need to be brought up to acceptable ecological status through the implementation of ad hoc restoration plans. Terminology and color coding according to EC (2000).

and Kowalik, 1991; Cicolani and Di Sabatino, 1991; Gerecke and Schwoerbel, 1991; Smit and van der Hammen, 1992; Growns, 2001; Dohet et al., 2008; Cicolani et al., 2009; Davies et al., 2010; Quiroga et al., 2010; Cîmpean, 2010). These studies have pointed out that water mites become scarce already in moderately polluted waters and tend to disappear altogether at highly impacted sites (e.g., urban or industrial discharge points) where other macroinvertebrates can still be found (Davies et al., 2010; Alvial et al., 2013). Furthermore, sensitive taxa tend to be replaced with tolerant taxa at sites with highly modified habitats (e.g., concretecovered banks) (Gerecke and Schwoerbel, 1991; van der Hammen and Smit, 1996; Growns, 2001). Water mite assemblages can be effective environmental indicators also because of the network of interactions with the rest of the benthic community on which mites depend to successfully complete their complex life cycle that includes distinct phases of parasitism, phoresy, predation, and competition (Proctor and Pritchard, 1989; Di Sabatino et al., 2008; Smit and Gerecke, 2010).

Despite sharing these characteristics with other macroinvertebrates, water mites are rarely utilized as bioindicators of pollution or disturbance (Resh and McElravy, 1993; Dohet et al., 2008). In the rare cases of inclusion in studies of invertebrate-environment associations and invertebrate-based indices of environmental quality, water mites are typically treated as a single taxonomic unit ("Hydrachnidia": e.g., Barber and Kevern, 1973; Pardo and Armitage, 1997; Kubošová et al., 2010; Alvial et al., 2013); however, water mites have been altogether excluded from the WFD list of biological parameters (Smit and Gerecke, 2010).

The main scopes of our work are 1. an assessment of water mite value as bioindicators based on an analysis of abundance and diversity as related to varied levels of pollution, and 2. the proposal of a numerical index of water quality for running-water ecosystems that includes water mites at family level.

\section{MATERIALS AND METHODS}

\section{> SAMPLE COLLECTION AND STUDY AREA}

The investigation is based on a total of 216 quantitative samples of lotic benthic macroinvertebrates collected with a Surber sampler (mesh size $0.47 \mathrm{~mm}$ ), mainly in riffle habitats. Sampling sites were never above $1000 \mathrm{~m}$ a.s.l. Samples cover a 25-year period (1986-2011) and were collected year-long in ice-free conditions at 81 locations distributed over 34 streams 


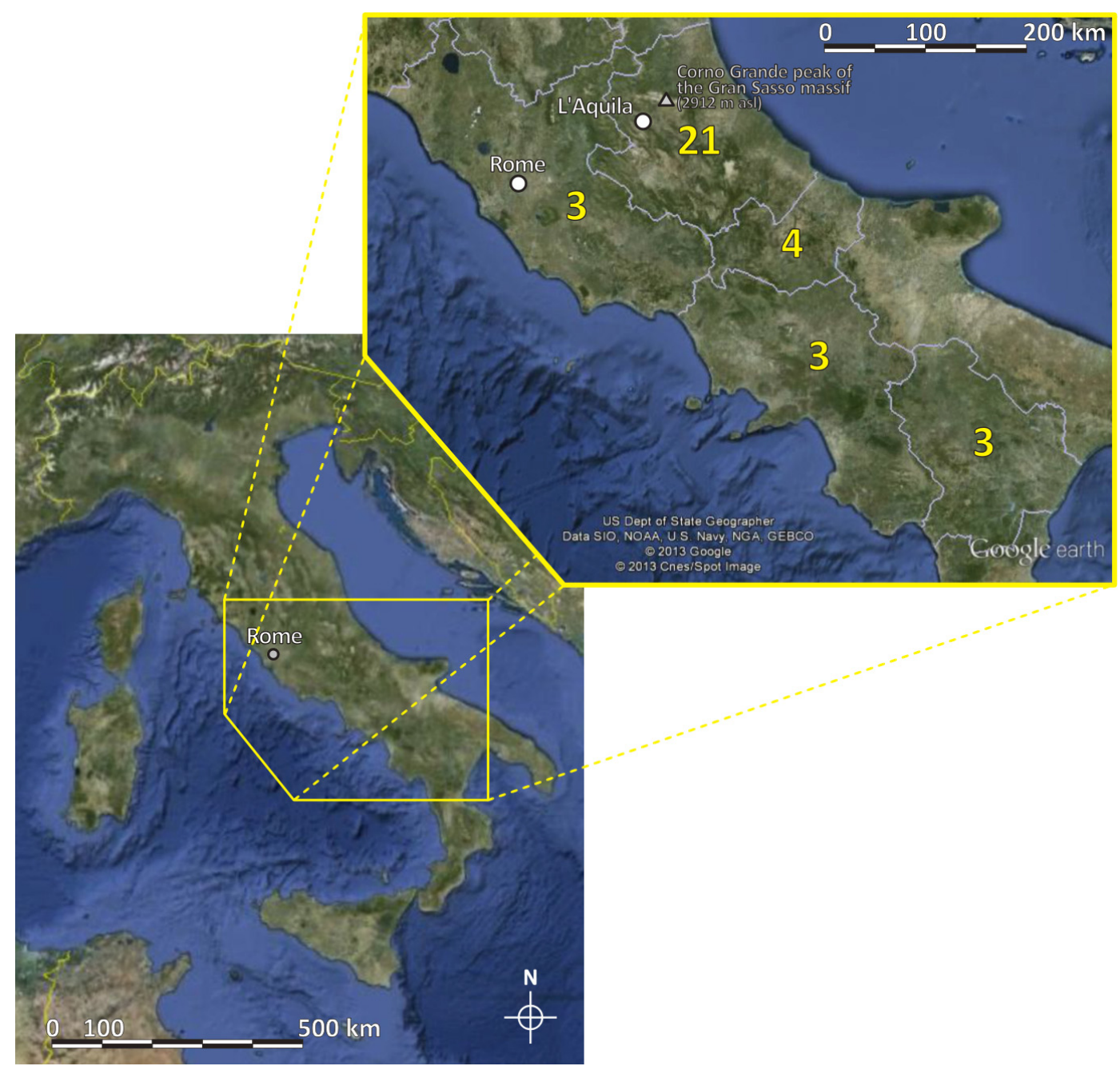

Figure 2

Study area and number of streams sampled, by administrative Region [Abruzzo: 21; Molise: 4; Latium, Campania and Basilicata (from NW to SE): 3 each]. Map elaborated from Google Earth images (C) 2013 Google \& Cnes/Spot Images).

in five administrative Regions in south-central Italy (Figure 2). Each site was visited 1-6 times; multiple visits (typically carried out within specific monitoring programs) were separated by at least two months. This area includes the Apennines that form a continuous NW-SE watershed ridge separating Adriatic from Thyrrhenic catchments. The Corno Grande peak (2912 m a.s.I.) of the Gran Sasso massif in Abruzzo is also the highest peak south of the Alps. Such highaltitude areas have an alpine climate. Much of the Gran Sasso massif and adjacent montane areas are organized in protected National and Regional Parks and Nature Reserves with minimal to nonexistent human presence. Most streams in this area are relatively short and present a gradient from torrential in the montane headwater to river-like in the lowlands; the latter are characterized by dense human populations and extensive urban, agricultural, and industrial land use. Most streams and rivers follow a general W-E course with final discharge into the Adriatic Sea. Such environmental and demographic characteristics lead to sampling localities distributed over a wide range of human impact and stream/river ecological status within a relatively small geographical area.

Sample collection and processing were carried out by the same laboratory, guaranteeing consistent methods and minimizing sampling variability. Samples were transported in coolers to the laboratory where they were immediately fixed in $75 \%$ ethilic alcohol. Hydrachnidia were fixed in Koenike solution following Di Sabatino et al. (2000). Macroinvertebrates were 


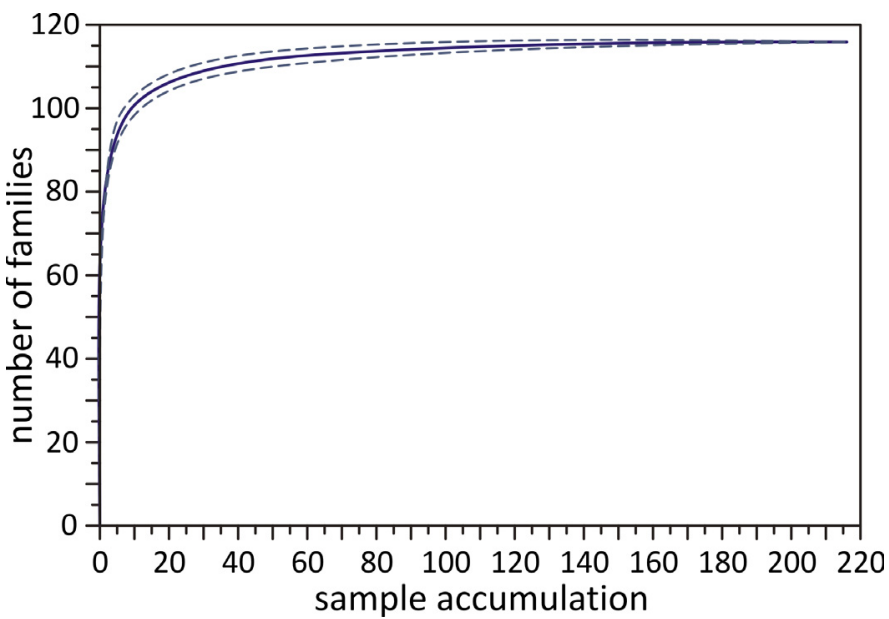

\section{Figure 3}

Family-based Coleman rarefaction curve for the 116 families of macroinvertebrates collected in the 216 samples. The curve was obtained with EstimateS (v. 8.2.0, () R.K. Colwell, University of Connecticut; http://viceroy.eeb.uconn.edu/estimates) using 50 randomizations per calculation routine, without replacement and without shuffling. Dashed lines represent the average \pm standard deviation interval.

identified at the stereomicroscope at species to family level. A total of 17823 individuals $\mathrm{m}^{-2}$ distributed over 116 families were found. Water mites comprised 16 families and 77 taxa, 74 of which identified at species level and 3 at genus level. A family-based Coleman rarefaction curve (Figure 3) revealed that $95 \%$ and $99 \%$ of the observed 116 families were accounted for after 34 and 90 samples, respectively, indicating that the grand total of 216 samples was more than adequate for the investigation. No singletons or doubletons (families represented by only one or two individuals, respectively) were observed. Minimum and maximum mite density per sample and per family were 3 and 800 individuals $\mathrm{m}^{-2}$ of substrate, respectively. Hydrachnidia have been the focus of a detailed quantitative analysis aimed at finding a relationship between the water mite taxocoenosis and local water quality; the latter has been evaluated by means of six macroinvertebrate-based biotic indices: STAR-ICMi, BMWP, ASPT, IBE, PTH, and the newly proposed index $\mathrm{PTH}_{\text {fam }}$.

\section{> DESCRIPTION OF BIOTIC INDICES}

We included six macroinvertebrate-based indices that directly relate to biotic (water) quality. The Star-ICMi index (Buffagni et al., 2008) is the pan-European standardized index for WFD implementation, and has recently (2010) been officially adopted by Italy for the same purpose. The BMWP and ASPT indices are based on taxon-specific tolerance scores and have widespread use in a number of countries since their introduction in the 1980s; however, water mites are now excluded from index calculations after inclusion (as "Hydrachnidia") in the original formulations. The IBE index is the index used in Italy before the adoption of the WFDcompliant Star-ICMi index. The PTH index has been utilized only once previously (Miccoli et al., 2006), but is the first index to focus on water mites along with other important taxa. Finally, we propose a new index, the $\mathrm{PTH}_{\text {fam }}$, which has been derived from the PTH but is based on a finer taxonomic resolution.

STAR-ICMi. The STAndardization of River Classifications - Intercalibration Multimetric Index (Buffagni et al., 2008, and references therein) integrates six different metrics:

- total number of observed families;

- number of plecopteran, trichopteran, and ephemeropteran families (EPT index);

- average score per taxon (ASPT index, as ASPT-2: Bennett et al., 2011);

- Shannon-Wiener diversity index $H^{\prime}$ calculated with natural logarithms;

- 1 - relative abundance of gastropods, oligochaetes, and dipterans (1 - GOLD); 
- the base-10 logarithm of the total abundance of selected families of ephemeropterans, plecopterans, trichopterans, and dipterans, corrected with $a+1$ constant to produce a zero-to- $\infty$ scale [log (sel EPTD + 1)].

These six metrics aim at expressing a synthetic information on the tolerance to disturbed conditions, the structure (richness, diversity) and the abundance-habitat relationship of the macroinvertebrate community. To this end, the STAR-ICMi index assigns different weights to the six metrics in an attempt to balance the three aspects that define the ecological condition of the community as outlined above: the number of families, the EPT index, and the ShannonWiener index describe the structure of the community; the ASPT index describes the taxonspecific degree of tolerance to pollution; and the 1-GOLD and log (sel EPTD + 1) metrics describe the abundance-habitat relationship of the macroinvertebrate community.

BMWP. THE BMWP index (Biological Monitoring Working Party: Alba-Tercedor et al., 1988) is based on taxonomic resolution at family level, with a score that represents each family's sensitivity or tolerance to pollution or disturbance sensu latu. Scores vary from 1 to 10 , with 10 representing the highest sensitivity or lowest tolerance to pollution/disturbance. The total or site score is given by the sum of all the family-specific scores at the site. The BMWP index has been subsequently standardized following regional or national surveys, and score thresholds have been established to define the five QCs according to WFD guidelines (Figure 1).

ASPT. The ASPT index (Average Score Per Taxon: Armitage et al., 1983) is obtained by dividing the BMWP index value by the number of observed families, which renders the index independent of taxonomic richness. The ASPT index also appears to be less site-specific and less sensitive to seasonal variations in macroinvertebrate community structure than the BMWP from which it is derived. Typically, ASPT values $>6$ are indicative of unimpacted waters, while index values $<4$ identify highly impacted sites (Mandaville, 2002).

IBE. The Indice Biotico Esteso (or Extended Biotic Index: Ghetti, 1997) had been the official Italian index until the adoption of the WFD-compliant Star-ICMi in 2010. The IBE index quantifies the effect of physico-chemical water quality on benthic macroinvertebrates that spend at least part of their life cycle in lotic ecosystems and identifies five QCs, from I (minimally impacted) to $\mathrm{V}$ (highly impacted).

PTH. The PTH index (Miccoli et al., 2006) is based on the presence/absence of Plecoptera, Trichoptera and Hydrachnidia. The choice of such groups is based on their sensitivity to environmental stress and their high degree of ecological specialization. Each group contributes to the PTH score differently, according to its "ecological value" and contribution to community functionality. The combination of the presence/absence of these three groups gives scores from zero (no plecoptera, trichoptera, or hydrachnidia found) to 6 (simultaneous presence of the three groups), for a total of seven possible QCs. The three worst quality classes have been lumped into one (QC V) for the purposes of this study. The PTH index was originally developed to evaluate the water quality of spring ecosystems.

$\boldsymbol{P T H}_{\text {fam }}$. This newly proposed index is the total number of plecopteran, trichopteran, and hydrachnidian families found at a site. This index is a reelaboration of the PTH index at a finer taxonomic level, and is the first benthic macroinvertebrate index to include water mites at family level. The PTH $\mathrm{P}_{\text {fam }}$ index identifies five QCs based on semiquantitative mite, plecopteran, and trichopteran distribution patterns relative to general stream ecological status; on other indices; and on our expert judgment (Table I). The full rationale for the choice of QC-specific $\mathrm{PTH}_{\mathrm{fam}}$ values is not reported here for the sake of conciseness, but the strictly quantitative verification is.

\section{> STATISTICAL ANALYSIS}

The BMWP and ASPT indices have been calculated using the ASTERICS 3.3.1 ${ }^{\circ}$ AQEM/STAR Ecological River Classification System free software, developed by the University of Duisburg-Essen (available at http://www.fliessgewaesserbewertung.de/en/download/ berechnung/). The remaining indices were calculated using $\mathrm{MS}^{\circledR} \mathrm{Excel}$, including longestablished macros to calculate the IBE. The six metrics for the calculation of the Star-ICMi 


\section{Table I}

Quality classes (QCs) in relation to $P T H_{\text {fam }}$ index values; verbal description and color code as per WFD guidelines. Roman numerals indicate QC denomination as used in this study.

\begin{tabular}{|l|c|c|c|}
\hline \multicolumn{3}{|c|}{ QC } & PTH $_{\text {fam }}$ \\
\hline high & I & & $\geqslant 10$ \\
\hline good & II & & $7-9$ \\
\hline moderate & III & & $4-6$ \\
\hline bad & IV & & $1-3$ \\
\hline poor & $\mathrm{V}$ & & 0 \\
\hline
\end{tabular}

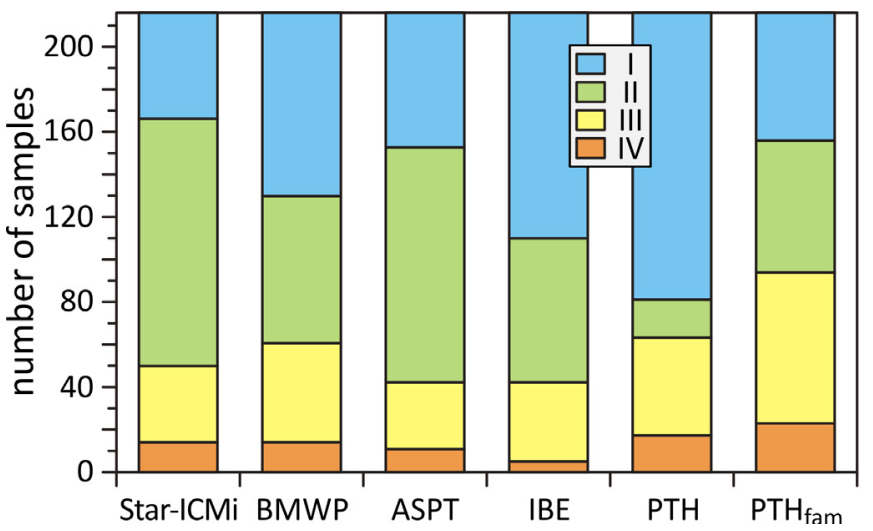

Figure 4

Number of samples per quality class (QC, I through IV) for the six macroinventebrate-based indices used in this investigation. Index description is in main text.

index were independently calculated and then merged per the index formula. Manual rounding was performed only at the end of the iterations. Water mite data analysis was performed using the most common families (i.e., families with frequency of occurrence $\geqslant 5$ ) to avoid unknown outlier incidence due to rarely encountered families. Appendix Tables A-I and A-II report unelaborated species-specific mite data.

QC and water mite distributions within each index were tested with one-way ANOVAs followed by Honestly Significant Difference (HSD) Tukey tests for significant ANOVAs. The HSD multiple comparison test effectively controls the family-wise Type I error to no more than the nominal level (Quinn and Keough, 2002: 199-200), with no need for Bonferroni corrections. QC distributions within each index were roughly normal (as determined from frequency distributions) but skewed to the left or to the right (symmetry test after Zar, 2009). QC data were therefore square-power-transformed $\left(x^{\prime}=x^{2}\right)$ if left-skewed or log-transformed $\left[x^{\prime}=\log (x+1)\right]$ if right-skewed (Zar, 2009) before use in ANOVAs and HSD tests. Mite density data were square-root-transformed $\left[x^{\prime}=\sqrt{x}\right]$ before ANOVAs/HSD tests (Zar, 2009).

Correlations run for selected datasets used untransformed data because of technique reliability when nonnormality is not extreme (Zar, 2009). Best-fitting trends (based on $r$ values) are reported. Affinity of the six indices was tested with an Agglomerative Hierarchical Clustering $(\mathrm{AHC})$ analysis based on observational data $(n=216)$ with similarity based on inertia and agglomeration based on average linkage, with automatic truncation (Quinn and Keough, 2002).

Significance threshold was set at $p \leqslant 0.05$ for all statistical tests. All statistical analysis was performed with Addinsoft ${ }^{\mathrm{TM}}$ XLSTAT $^{\mathrm{TM}}$ 2012.6.09.

\section{RESULTS}

Most sites were classified in high or good ecological status by all six indices (Figure 4). On average, approximately $76 \%$ of the sites were classified as QC I or II, and $24 \%$ as QC III or IV 


\section{Table II}

Results of the skewness test (Zar, 2009) of QC distribution within each of the six tested indices, for which maximum right skewness (i.e., frequency distribution with an elongated right tail and therefore accumulation of observational data to the left of the average value) is $\sqrt{b_{1}}=(n-2) / \sqrt{n-1}=14.59(n=216)$, maximum left skewness (i.e., frequency distribution with an elongated left tail and accumulation of data to the right of the average value) is $-\sqrt{b_{1}}=-14.59$, and symmetry is for $\sqrt{b_{1}}=$ zero.

\begin{tabular}{|l|c|}
\cline { 2 - 2 } \multicolumn{1}{c|}{} & $\sqrt{b_{1}}$ \\
\hline Star-ICMi & -0.751 \\
\hline BMWP & 0.131 \\
\hline ASPT & -0.711 \\
\hline IBE & -0.443 \\
\hline PTH & -0.928 \\
\hline PTH $_{\text {fam }}$ & 0.316 \\
\hline
\end{tabular}

\section{Table III}

Proportions of water mite density, number of species, and number of families (based on numbers per $\mathrm{m}^{-2}$ of substrate, as \% of respective totals) in QCs I + II and III + IV according to the six indices, based on the total of the 216 samples collected.

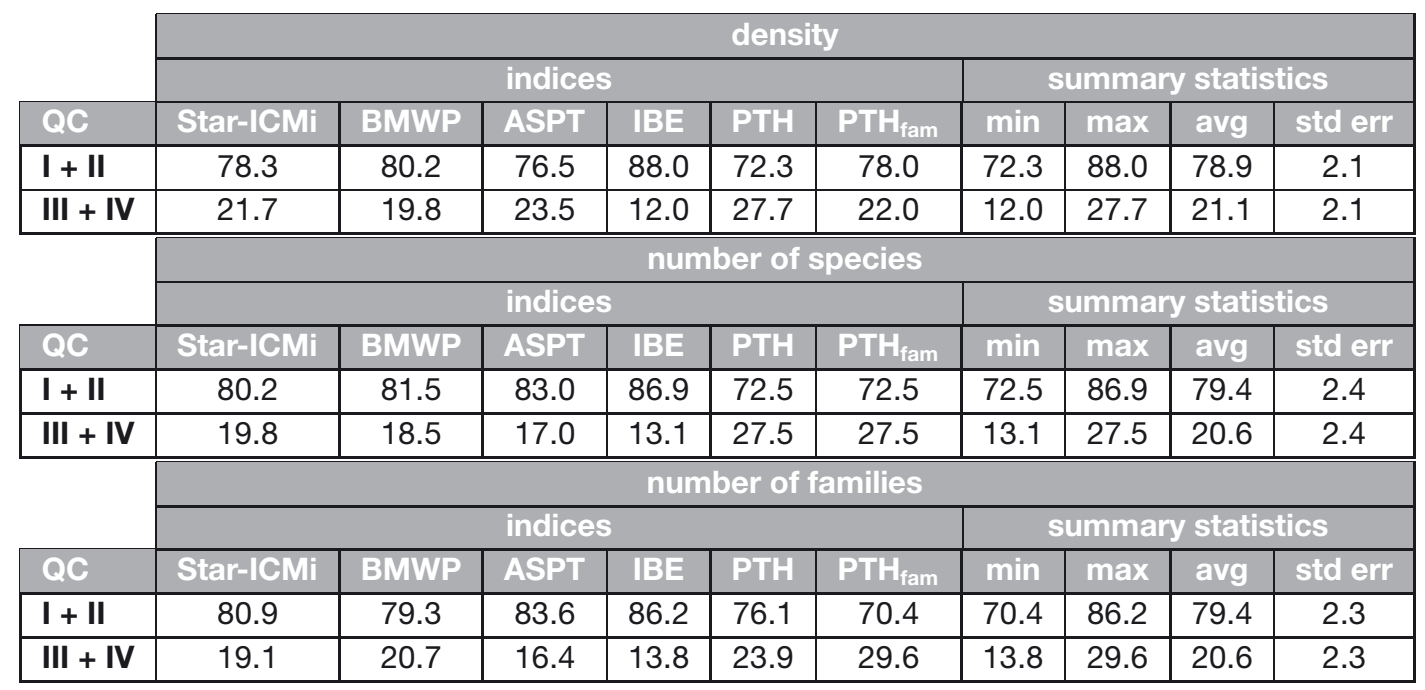

(standard error $=2.1 ; n=6$ ). Our survey did not find any site in poor ecological status (QC V). QC separation was complete and highly significant for all indices (one-way, type I ANOVAs for each index, performed on square-power- or log-transformed data to correct for skewness: $F=371.469-7026.712, d f=3.212$ and $p<0.0001$ for all; complete HSD separation at $p<0.0001$ for all). Frequency distribution was almost symmetrical for the BMWP index and, to a lesser extent, for the $\mathrm{PTH}_{\text {fam }}$ and IBE indices, while distribution for the remaining indices was relatively asymmetrical (Table II). The slightly asymmetrical distribution for the BMWP and $\mathrm{PTH}_{\text {fam }}$ indices was right-skewed, while the more markedly asymmetrical distributions for the other indices were left-skewed, with accumulation of distribution data to the right of the average value (i.e., average $>$ median) (Table II).

On average, $~ 70-88 \%$ of water mite density, number of species, and number of families were found in QC I and II (Table III, Figure 5). Mite distribution in QCs I and II was consistently lowest for the PTH index and highest for the IBE index, with mite distribution in QC I + II for the other indices at intermediate levels (Table III). Water mite representativeness in QC I + II tended to increase with decreasing taxonomic resolution for the ASPT index, and to decrease with decreasing taxonomic resolution for the $\mathrm{PTH}_{\text {fam }}$ index, while no pattern was discernible for the remaining indices (Table III).

The majority of QC-exclusive species- or genus-level taxa (hereafter "species") of Hydrachnidia were found in QC I or II across the six indices (Table IV and Appendix Table A-I). Most 

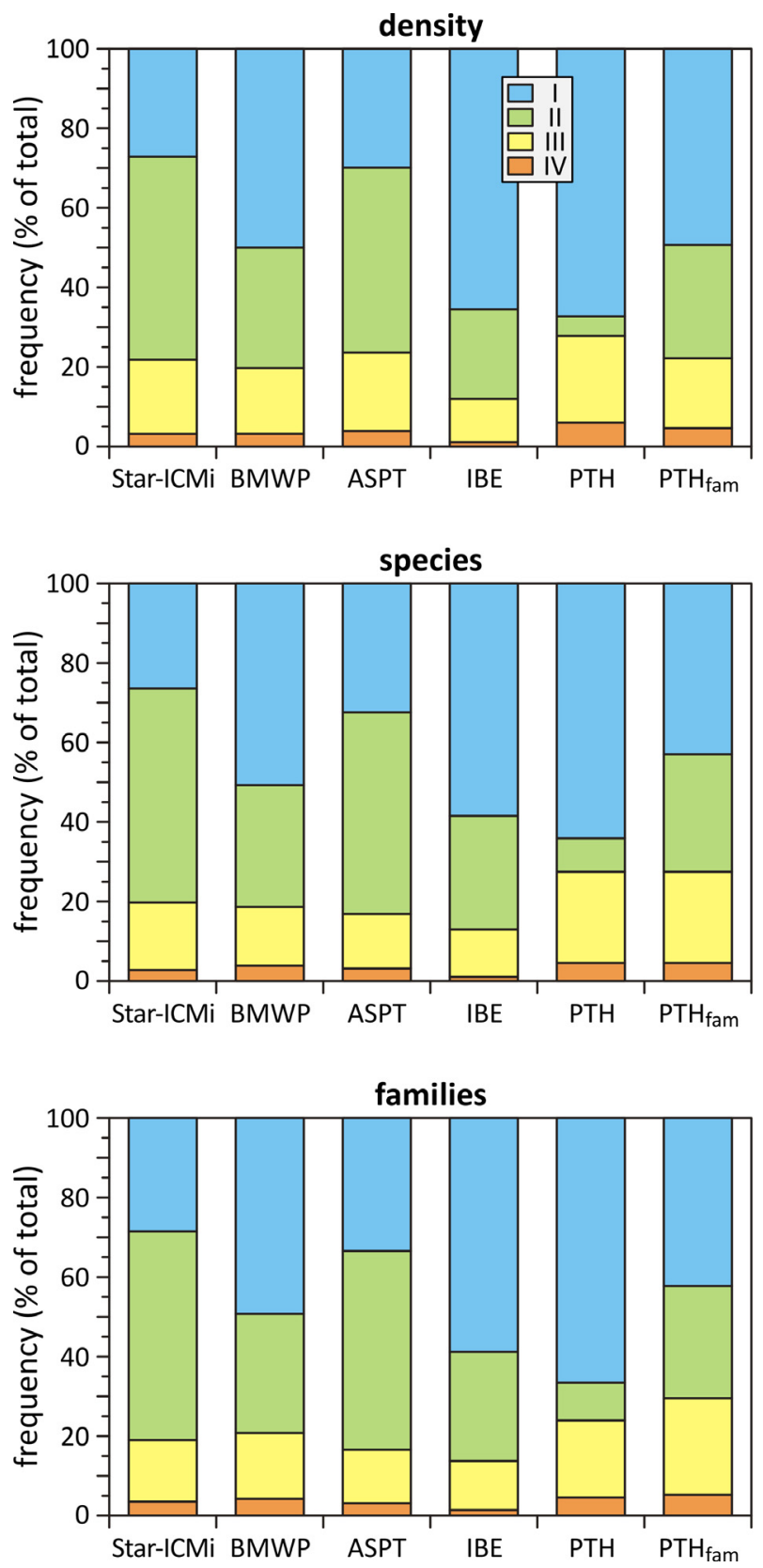

Figure 5

Distribution (as percent of corresponding totals) of water mite density, number of species, and number of families across the four observed QCs (I-IV) for the six indices.

of the QC-exclusive mite species tended to be placed in QC I by most indices, except by the Star-ICMi and ASPT indices. Approximately 1/4 (ASPT) to 3/4 (BMWP) of mite species were found in QC I and/or II (Table V). The percentage of mite species found across the acceptable/unacceptable threshold for ecological status sensu the WFD (i.e., species found in QC I and/or II and in QC III and/or IV) ranged from 25\% (BMWP) to 57\% (Star-ICMi and ASPT) (Table V). The pattern was similar for mite families, with 12\% (ASPT) to 50\% (IBE) of the mite families found in QC I and/or II, and $\sim 44 \%$ (BMWP) to 69\% (ASPT) of mite families found in QC I/II and QC III/IV (Table V).

Distribution of the most common species of Hydrachnidia, such as Feltria zschokkei (Feltriidae), Atractides nodipalpis, A. pennatus, Hygrobates fluvialitis (Hygrobatiidae), and Lebertia sparsicapillata (Lebertiidae) was unrelated to stream QC, with presence of these taxa 


\section{Table IV}

Number of species- or genus-level taxa of Hydrachnidia found exclusively in QC I, II, III, or IV, according to the six indices. Total number of mite species/genus-level taxa was 77.

\begin{tabular}{|l|c|c|c|c|}
\cline { 2 - 5 } \multicolumn{1}{c|}{} & \multicolumn{4}{|c|}{ QC } \\
\cline { 2 - 5 } \multicolumn{1}{c|}{} & \multicolumn{1}{|c|}{} & \multicolumn{1}{|c|}{} & $\mathrm{III}$ & $\mathrm{I}$ \\
\hline Star-ICMi & 2 & 18 & 4 & 1 \\
\hline BMWP & 30 & 1 & 2 & - \\
\hline ASPT & 5 & 8 & 11 & 1 \\
\hline IBE & 22 & 2 & 2 & - \\
\hline PTH & 23 & - & 4 & 2 \\
\hline PTH $_{\text {fam }}$ & 19 & 3 & 2 & 1 \\
\hline
\end{tabular}

\section{Table $V$}

Number of species- or genus-level taxa (top panel) and families of Hydrachnidia (bottom panel) found in QCs I and/or II or in two or more QCs across the acceptable/unacceptable threshold in EQR, according to the six indices. Total number of mite species/ genus-level taxa was 77 and total number of families was 16.

\begin{tabular}{|l|c|c|}
\hline \multicolumn{3}{|c|}{ species and genera } \\
\hline \multirow{2}{*}{} & \multicolumn{2}{|c|}{ QC } \\
\cline { 2 - 3 } & I and/or II & I/II and III/IV \\
\hline Star-ICMi & 28 & 44 \\
\hline BMWP & 56 & 19 \\
\hline ASPT & 20 & 44 \\
\hline IBE & 48 & 27 \\
\hline PTH & 30 & 40 \\
\hline PTH $_{\text {fam }}$ & 35 & 38 \\
\hline \hline \multicolumn{3}{|c|}{ families } \\
\hline \multicolumn{3}{|c|}{ QC } \\
\cline { 2 - 3 } & I and/or II & I/II and III/IV \\
\hline Star-ICMi & 6 & 10 \\
\hline BMWP & 6 & 7 \\
\hline ASPT & 2 & 11 \\
\hline IBE & 8 & 8 \\
\hline PTH & 6 & 10 \\
\hline PTH & 7 & 9 \\
\hline
\end{tabular}

observed in all QCs (Appendix Table A-I). Among the less common species found exclusively in QC I and/or II by all indices was Protzia rugosa (Hydryphantidae); all other species restricted to QC I and/or II were rare, sometimes found in only one sample and/or with fewer than 10 individuals $\mathrm{m}^{-2}$ (Appendix Tables $\mathrm{A}-\mathrm{I}$ and $\mathrm{A}-\mathrm{II}$ ).

Water mite species and family accumulation curves (Figure 6) followed expected logarithmic trends, despite high variability at high mite densities. On average, maximum water mite species richness was about 8 and maximum family richness was about 5 per sampling site (Figure 6). No singletons or doubletons (species or families represented by a single or two individuals, respectively) were found.

Most indices were able to discriminate water mite species and family richness by QC to some extent (Figure 7, Table VI). Mite distribution was more clearly separated across the four QCs at family than species level (two-tailed paired $t$-test on log-transformed $F$ values: $t=-4.565$; $n=6$ and $d f=5 ; p=0.0060$ ). Even at family level though, the $\mathrm{PTH}_{\text {fam }}$ remained the only index capable of fully and completely discriminating water mite distribution among QCs, including the crucial difference between QC II ("acceptable ecological status" according to the WFD: Figure 1) and QC III ("unacceptable ecological status") (Figure 7, bottom panels). Most other indices either separated water mite distribution in QC I from all other QCs (e.g., BMWP, IBE) or they separated mite distribution in QC IV from all the others (e.g., Star-ICMi and PTH at species level). 

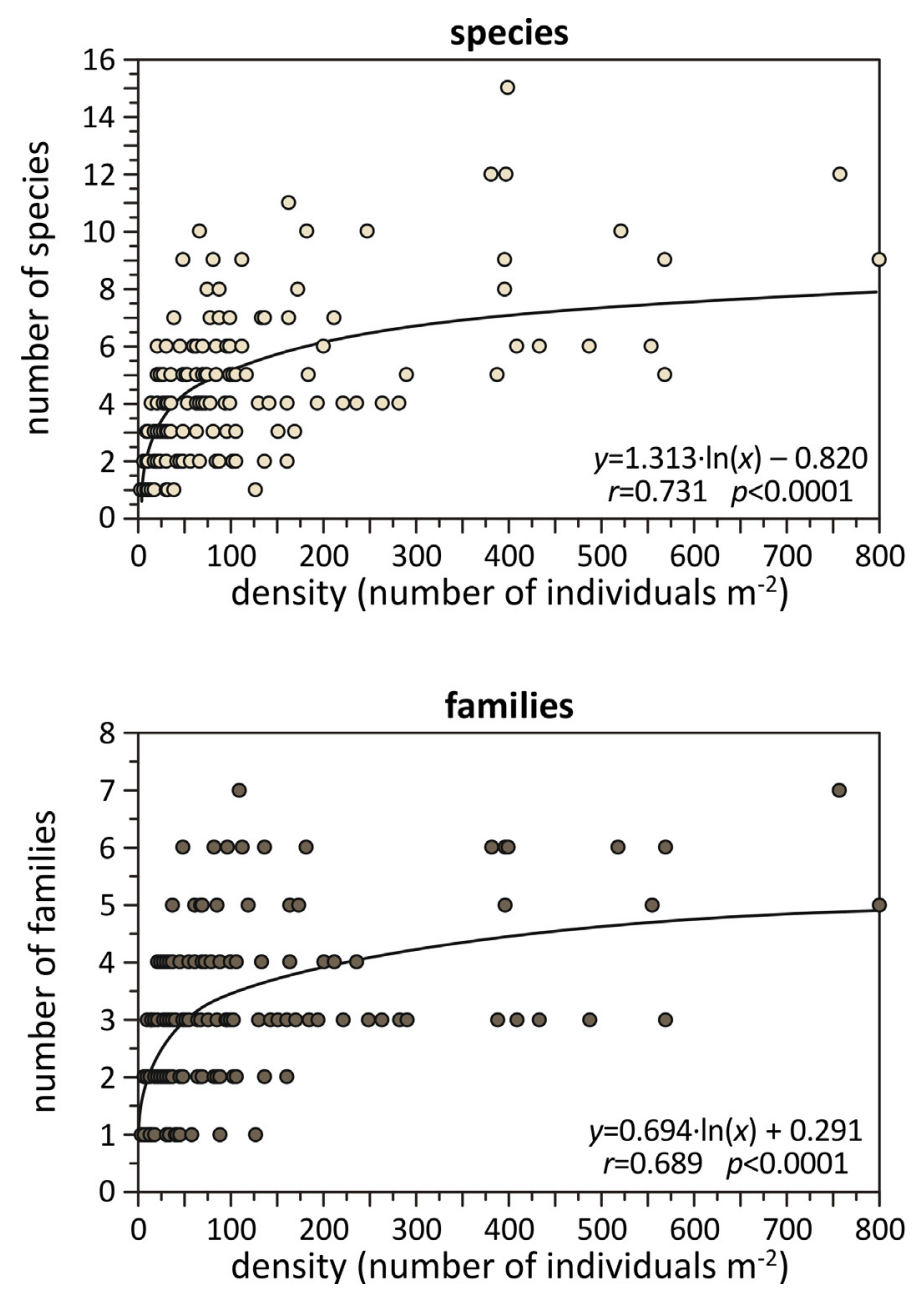

\section{Figure 6}

Number of water mite species (top) and families (bottom) in relation to mite density, by sampling site $(n=216$ and $d f=214$ for each). Correlations were performed on untransformed data.

Best fits between the $\mathrm{PTH}_{\text {fam }}$ and the other indices were linear for the BMWP and logarithmic for the remaining indices (Figure 8), though the linear relationship was almost as descriptive for the IBE $\left(r_{\text {linear }}=0.711\right)$. The "flattening" of the logarithmic trend occurred at $\mathrm{PTH}_{\mathrm{fam}} \approx 4-5$ for all logarithmic relationships (Figure 8), i.e., it included PTH $_{\text {fam }}$ values for QCs I, II, and III (Table I).

An agglomerative hierarchical cluster (AHC) analysis similarly identified the ASPT and PTH indices as separate from the group formed by the Star-ICMi, IBE, BMWP, and $\mathrm{PTH}_{\text {fam }}$ indices (Figure 9). In particular, the newly proposed $\mathrm{PTH}_{\text {fam }}$ was closest to the BMWP index and secondarily to the IBE index, while the WFD-accepted Star-ICMi index resulted relatively separated from the core of the most similar indices (Figure 9).

\section{DISCUSSION}

Hydrachnidia and index distribution across quality classes (QCs) were generally concordant, with most sites classified as QC I or II (WFD classes of "high" and "good" ecological status, both above the acceptability threshold: Table I) and most of Hydrachnidia found in such QCs (Tables III-V; Figures 4-5), suggesting a high potential of water mites as bioindicators of unimpacted lotic sites (Growns, 2001; Cicolani et al., 2009; Davies et al., 2010; Smith et al., 2010). However, the overall poor performance of the PTH index (Figures 7-9), based on simple, 

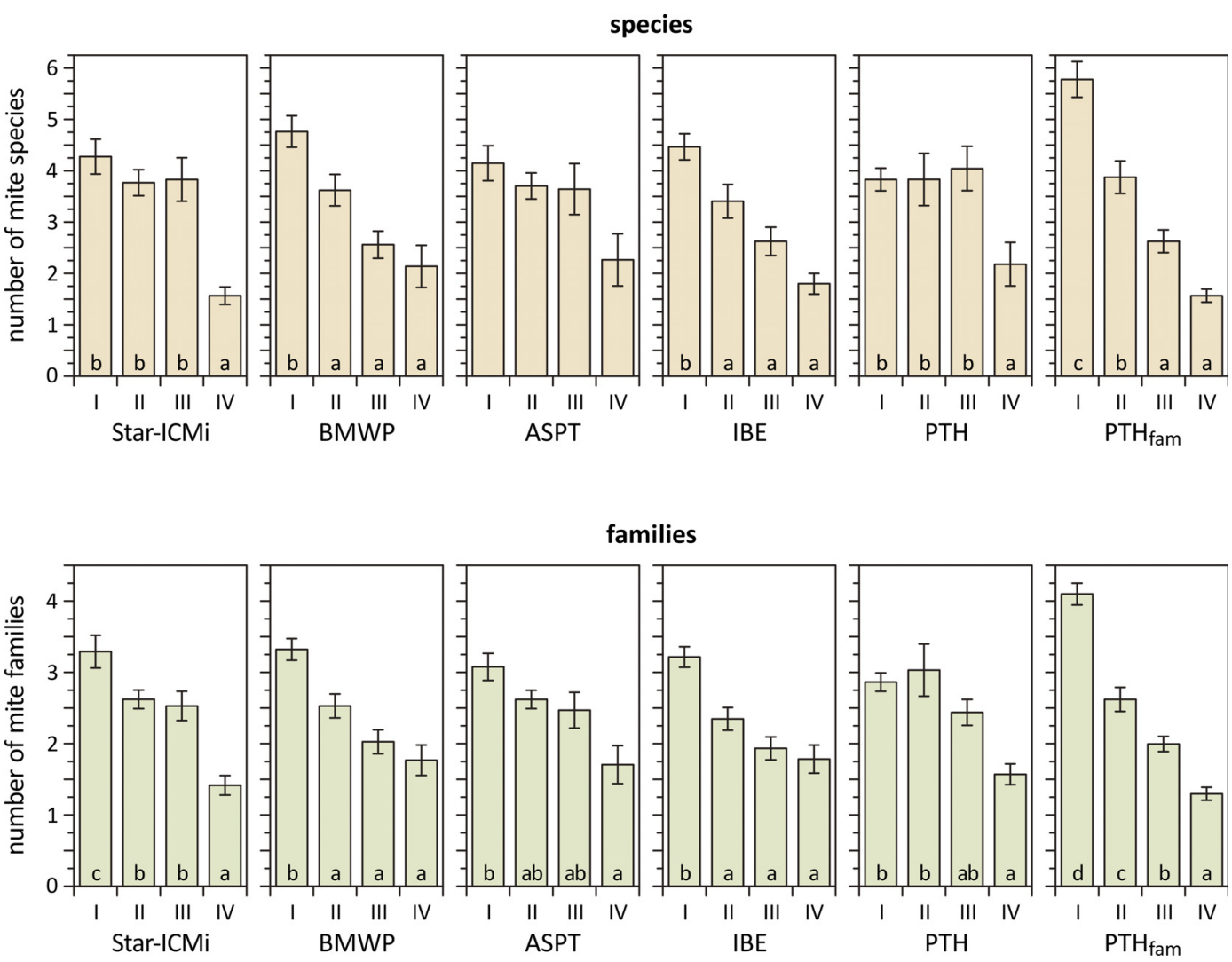

Figure 7

Average ( \pm standard error) water mite species (top) and families (bottom) by QC (I-IV) according to each of the six indices, using sampling sites as replicates. Different letters indicate significantly different average values $(p \leqslant 0.05)$ within each panel according to a posteriori Tukey HSD multiple tests following significant one-way, type I ANOVAs. Complete ANOVA results are reported in Table VI.

\section{Table VI}

Results of the one-way ANOVAs relative to Figure 7, performed on square-root-transformed count data; $d f=3,212$ for each test.

\begin{tabular}{|l|c|c|c|c|}
\cline { 2 - 5 } \multicolumn{1}{c|}{} & \multicolumn{2}{c|}{ species } & \multicolumn{2}{c|}{ families } \\
\cline { 2 - 5 } \multicolumn{1}{c|}{} & $F$ & $\rho$ & $F$ & $\rho$ \\
\hline Star-ICMi & 5.389 & 0.001 & 7.262 & 0.0001 \\
\hline BMWP & 12.458 & $<0.0001$ & 12.838 & $<0.0001$ \\
\hline ASPT & 1.976 & 0.119 & 3.490 & 0.017 \\
\hline IBE & 7.691 & $<0.0001$ & 10.758 & $<0.0001$ \\
\hline PTH & 2.944 & 0.034 & 5.007 & 0.002 \\
\hline PTH $_{\text {fam }}$ & 37.150 & $<0.0001$ & 55.756 & $<0.0001$ \\
\hline
\end{tabular}

direct presence/absence of Hydrachnidia as a group (Miccoli et al., 2006) strongly suggests that inclusion of water mites as a single group is not suitable for ecological status assessment in lotic systems beyond the stream head as the PTH index was originally designed for and applied in spring habitats (Miccoli et al., 2006). Such a consideration is sensible, as most taxa of Hydrachnidia in spring habitats would be roughly equivalent as bioindicators of unimpacted habitats, while water mites encountered along a stream course include a mixture of impact-sensitive and impact-tolerant taxa (Appendix Table A-I).

Bioindicator value for Hydrachnidia appears to be limited also as density, as density-based species and family accumulation curves tended to flatten at $\sim 8$ and $\sim 5$ species or families respectively when density reached $\sim 200$ individuals $\mathrm{m}^{-2}$ (Figure 6), indicating that further increases in density do not lead to increased mite diversity. Dense populations of common mite species, such as F. zschokkei, A. nodipalpis, A. pennatus, L. sparsicapillata, and especially 

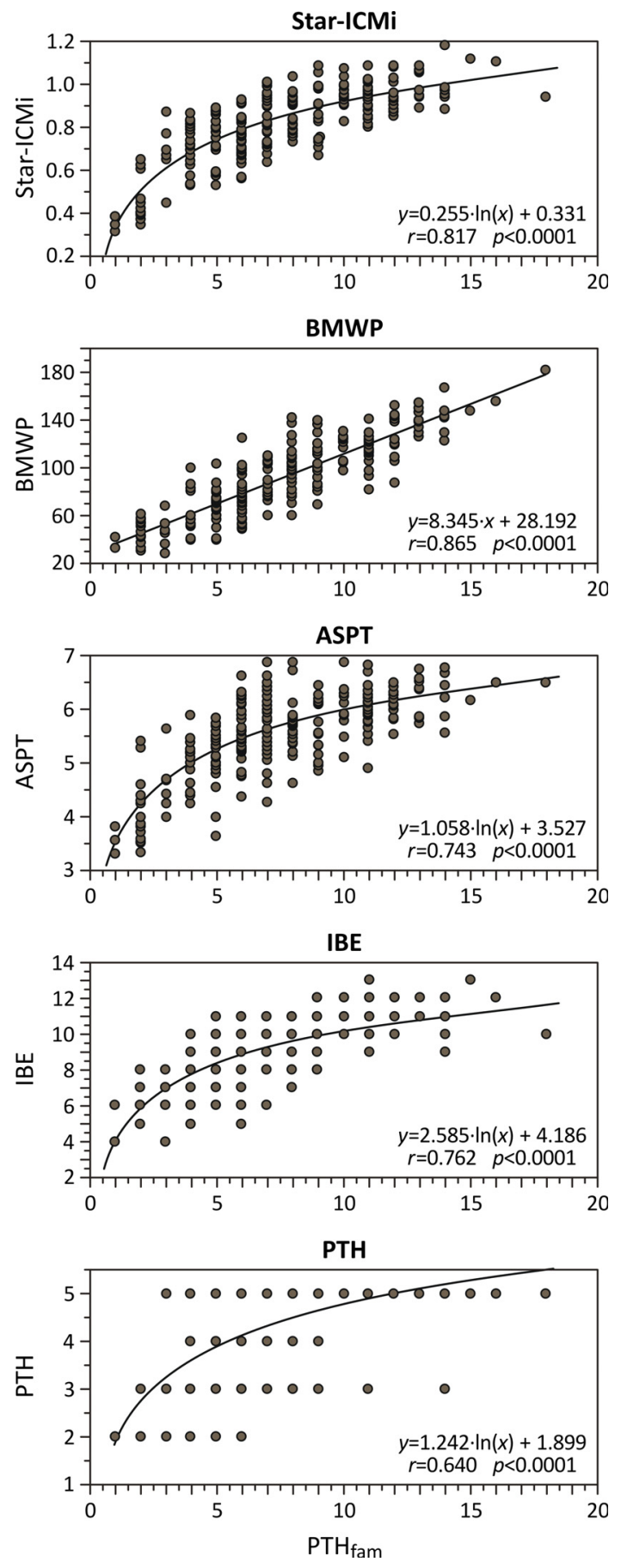

\section{Figure 8}

Correlations between the $\mathrm{PTH}_{\mathrm{fam}}$ and the other five indices considered in this study. Best-fit curve is reported for each correlation. Correlations were run on untransformed data; $n=216$ for each.

the widespread $H$. fluvialitis, were found across the whole range of QCs (Appendix Table A-I), strongly suggesting that mite density as such should be discarded as a metric to assess stream ecological status. Basic biological metrics such as abundance and density were found to be unreliable as descriptors of river ecological status also elsewhere (Thiébaut et al., 2006; Lewin et al., 2013).

Most impact-sensitive species of Hydrachnidia were uncommon to very rare (Appendix Table A-I), probably also reflecting their dependence on a restricted ensemble of semiaquatic 


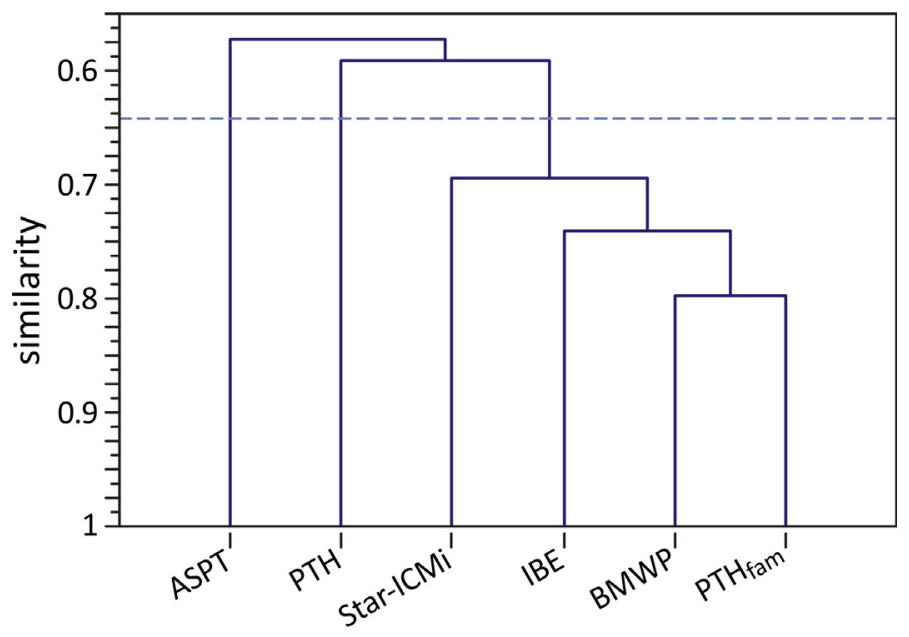

Figure 9

Agglomerative hierarchical clustering $(A H C)$ for the six indices, performed on observational data (index values) with similarity based on inertia and agglomeration method based on average linkage, with automatic truncation. The horizontal dashed line represents the AHC-calculated point of separation of the three main groups of indices (ASPT; PTH; and Star-ICMi-IBE-BMWP-PTH fam $_{\text {). }}$

insects (which may be impact-sensitive themselves) to complete their complex life cycle (Di Sabatino et al., 2000). Only one mite species as such (P. rugosa) was sufficiently impact-sensitive and relatively common to potentially serve as a direct bioindicator (Appendix Table A-I), further suggesting that the inherently difficult identification of water mites at species level for the purpose of WFD-compliant monitoring and assessment may not be worth the effort.

Distribution of mites in QC I + II (or across the WFD "acceptability" threshold) was similar at species and family level (Table V), and species- and family-based patterns in the distribution of Hydrachnidia also were similar (Figure 5), suggesting that these taxonomic levels are potentially roughly equivalent for bioindication purposes. A clearer separation of average number of mite families than species across QCs (Figure 7, Table VI, and $p<0.0001$ for the paired $t$-test for family-vs.-species based $F$ values) further suggests that inclusion of $\mathrm{Hy}$ drachnidia in biotic indices may be more reliable at family than species level, without the need for time-consuming and laborious identification at species level, which often can be carried out reliably only by highly specialized taxonomists.

Regardless of inclusion or exclusion of Hydrachnidia in their formulations, all indices discriminated between QCs $(p<0.0001$ for all index-specific one-way ANOVAs and related HSD tests). All indices were also highly correlated with one another $(p<0.0001$ for pairwise linear correlations; detailed results not shown), indicating that their general behavior as descriptors of stream ecological status is roughly equivalent. The quantitatively/statistically tested behavior of the $\mathrm{PTH}_{\text {fam }}$ index generally similar to the other indices (Figures $4,5,7$ ) indicates that our original choice of $\mathrm{PTH}_{\mathrm{fam}}$-based QCs (Table I), based on semiquantitative observations, was correct and reliable.

Frequency distribution of index values was quasi symmetrical only for the $\mathrm{BMWP}$, the $\mathrm{PTH}_{\mathrm{fam}}$, and to a lesser extent, the IBE indices, while distribution for the remaining indices (Star-ICMi, ASPT and PTH) was left-skewed (Table II), indicating that the latter indices tend to inflate and possibly misidentify QCs at high index values (i.e., QCs I, II, and possibly III). The StarICMi, ASPT, and PTH indices also had the highest degree of failure to assign mite families to either the QC I + II or the QC III + IV categories (number of families across the WFD acceptability threshold $\geqslant 10$ : Table $\mathrm{V}$ ). Index ability to incorporate mite information at family level thus appears to be closely associated with ability to discern QCs in an unbiased fashion, with the less biased indices (those with quasi symmetrical distribution in Table II) also better able to assign water mite families across fewer QCs (Table V). 
The ASPT and PTH indices additionally failed to discriminate the distribution of Hydrachnidia across all QCs (nonsignificant ANOVAs or incomplete HSD separation in Figure 7). Such indices also stood apart according to the AHC analysis (Figure 9). Lewin et al. (2013) similarly found a general inability of the ASPT index to correctly identify reference sites in montane, (semi)pristine habitats, with an apparently excessively conservative behavior of the ASPT index, both in absolute terms and relative to the BMWP index. The only index to clearly and unequivocally assign different numbers of mite families across QCs was the $\mathrm{PTH}_{\text {fam }}$ (Figure 7), strongly suggesting that mite information for the purpose of water quality assessment is most reliable when incorporated in this index. The second-best statistical separation of Hydrachnidia families across QCs was for the Star-ICMi, which however failed to discriminate across the WFD acceptability threshold between QCs I/II and QCs III/IV (Figure 7), further supporting the better ability of the $\mathrm{PTH}_{\text {fam }}$ index as a macroinvertebrate-based descriptor of stream ecological status. Lyche Solheim et al. (2013) similarly found the highest sensitivity for simple indices, and only an intermediate ability for a relatively complex multi-metric index based on benthic macroinvertebrates to describe ecological (trophic) status in lake ecosystems, suggesting a limited power of overly integrative indices for monitoring purposes.

The $\mathrm{PTH}_{\text {fam }}$-BMWP correlation was the only linear one (Figure 8), reflecting the quasi symmetrical index value distributions of these two indices (Table II). All other correlations with the $\mathrm{PTH}_{\text {fam }}$ index were logarithmic, indicating that such indices become increasingly less sensitive to changes in benthic macroinvertebrate community structure as the ecological status improves toward (semi)pristine conditions. In fact, such indices behave like any logarithmbased indices, including the widely used Shannon-Wiener index of diversity $H^{\prime}$, which Testi et al. (2009) found incapable of discerning any change in ecological status along the increasingly impacted head-to-mouth course of a $\sim 120-\mathrm{km}$ river in central Italy. In contrast, the invertebrate-based IBE and a macrophyte-based index indicated decreasing ecological status as the river gradually entered the human-populated lowlands. Thiébaut et al. (2006) similarly found a presence/absence index based on sensitive macroinvertebrate taxa as the most reliable metric to describe river ecological status in northeastern France, while all logarithmbased diversity indices (including the $H^{\prime}$ index) resulted unreliable. Rossaro et al. (2011) also found the lowest correlation scores for the $H^{\prime}$ and a weighted $H^{\prime}$ index among nine benthic macroinvertebrate indices, as well as with physico-chemical variables, applied to northern Italian lakes. May (2011) strongly argued against the use of the Shannon-Wiener and other logarithm-based biotic indices on the grounds of their mathematical properties, which lead to asymptotic flattening at high values. Based on Figures 7 and 8, the assignment of sampling sites in QCs I, II, and/or III (PTH fam $_{2} \geqslant 4-5$ : Table I) by the Star-ICMi, ASPT, IBE, and PTH indices may be questionable. Accordingly, the AHC analysis identified the $\mathrm{PTH}_{\mathrm{fam}}$ and $\mathrm{BMWP}$ indices as the most similar, while the WFD-accepted Star-ICMi index remained at the margin of the group of the four most similar and reliable indices (Figure 9).

Its quantitative structure and ecological basis place the newly proposed $\mathrm{PTH}_{\text {fam }}$ index in the group of mathematically simple metrics based on incidence data (presence/absence), such as the EPT index based on the taxonomic richness of disturbance-sensitive ephemeropteran, plecopteran, and trichopteran insects (Barbour et al., 1992). The debate over which measureincidence or abundance - should provide the basis for general-purpose biological indices is still open (e.g., Maurer and McGill, 2011). Abundance-based indices may be more complete, but they give greater weight to common taxa (Washington, 1984; Maurer and McGill, 2011). As our mite taxocoenosis analysis also indicates (Appendix Tables A-I and A-II), common taxa usually have the lowest value as potential bioindicators while less common taxa are more typically associated with specific habitats. By giving the basic same weight to common and rare taxa, incidence-based indices may thus be more effective when a bioassessment of ecological status is needed. In fact, taxonomic richness as such or organized in a numerical index has been found to be among the most reliable metrics to describe riverine ecological status (Thiébaut et al., 2006; Lewin et al., 2013). Mjelde et al. (2013) similarly found that macrophyte abundance or abundance-based indices to assess lake ecological status performed less well than otherwise identical presence/absence-based metrics, further supporting the hypothesis 
that incidence-based metrics may be a more reliable tool to monitor the ecological status of freshwater ecosystems. Virtually all aspects of our quantitative analysis indeed suggest that the incidence-based $\mathrm{PTH}_{\text {fam }}$ index is the most robust and reliable among those tested for the purpose of macroinvertebrate-based rapid bioassessment of lotic ecosystems.

Our analysis demonstrates that relatively simple indices such as the BMWP and the newly proposed $\mathrm{PTH}_{\text {fam }}$ perform better and more reliably than the WFD-compliant Star-ICMi index, which is additionally based on a labor-intensive sampling design and data reduction. The BMWP and $\mathrm{PTH}_{\text {fam }}$ indices also are capable of detecting subtle changes in stream condition at high and good ecological status, potentially serving as sentinel indices at the onset of ecological deterioration. Furthermore, the $\mathrm{PTH}_{\text {fam }}$ is the only index truly capable of discerning mite patterns across the whole range of QCs (Figure 7). The $\mathrm{PTH}_{\text {fam }}$ has the additional advantage over the BMWP in its simplicity of sampling and straightforward, simple formulation without the need for region- or ecosystem-specific tolerance scores (e.g., Artemiadou and Lazaridou, 2005). Because of the derivation of the $\mathrm{PTH}_{\mathrm{fam}}$ from the montane spring PTH index (Miccoli et al., 2006) and an apparent inability of the BMWP index to correctly identify reference sites at high altitude (1200 m a.s.I.: Lewin et al., 2013), we urge further explorations into the applicability of the $\mathrm{PTH}_{\text {fam }}$ index to a wider range of stream ecosystem types.

In conclusion, we advocate the inclusion of Hydrachnidia at family level in the formulation of biotic indices and support the adoption of simple and user-friendly indices for WFD-compliant bioassessment of lotic ecosystems. Though further cross-validation is needed, also including site-specific data on physico-chemical variables, we believe that the newly proposed $\mathrm{PTH}_{\text {fam }}$ has a high potential for use in WFD-compliant and other rapid bioassessments of stream ecological status.

\section{ACKNOWLEDGEMENTS}

This study was funded by the Italian Ministry for the Environment and Protection of Natural Resources (project PR 348-UAQ) and the Sirente-Velino Regional Park. Profound thanks go to Dr. Antonio Di Sabatino and two anonymous referees for their constructive criticism on an earlier version of this paper, and to Ms. Tamar M. Rein (UC-Davis PD, California, USA) who kindly checked the MS for language.

\section{REFERENCES}

Alba-Tercedor J. and Sanchez-Ortega A., 1988. Un metodo rapido y simple para evaluar la calidad biologica de las aguas corrientes basado en el de Hellawell (1978). Limnetica, 4, 51-56.

Allan J.D., 2004. Landscape and riverscapes: The influence of land use on stream ecosystems. Annu. Rev. Ecol. Evol. Syst., 35, 257-284.

Allan J.D. and Flecker A.S., 1993. Biodiversity conservation in running waters. BioScience, 43, 32-43.

Alvial I.E., Orth K., Durán B.C., Álvarez E. and Squeo F.A., 2013. Importance of geochemical factors in determining distribution patterns of aquatic invertebrates in mountain streams south of the Atacama Desert, Chile. Hydrobiologia, 709, 11-25.

Armitage P.D., Moss D., Wright J.F. and Furse M.T., 1983. The performance of a new biological water quality scores system based on macroinvertebrates over a wide range of unpolluted running-water sites. Water Res., 17, 333-347.

Artemiadou V. and Lazaridou M., 2005. Evaluation score and interpretation index for the ecological quality of running waters in central and northern Hellas. Environ. Monit. Assess., 110, 1-40.

Barber W.E. and Kevern N.R., 1973. Ecological factors influencing macroinvertebrate standing crop distribution. Hydrobiologia, 43, 53-75.

Barbour M.T., Plafkin J.L., Bradley B.P., Graves C.G. and Wisseman R.W., 1992. Evaluation of EPA's Rapid Bioassessment Benthic Metrics: metric redundancy and variability among reference stream sites. Environ. Toxicol. Chem., 11, 437-449. 
Bennett C., Owen R., Birk S., Buffagni A., Erba S., Mengin N., Murray-Bligh J., Ofenböck G., Pardo I., van de Bund W., Wagner F. and Wasson J.-G., 2011. Bringing European river quality into line: an exercise to intercalibrate macro-invertebrate classification methods. Hydrobiologia, 667, 31-48.

Biesiadka E. and Kowalik W., 1991. Water mites (Hydracarina) as indicators of trophy and pollution in lakes. In: Dusbábek F. and Bukva V. (eds.), Modern Acarology, Academia Prague and SPB Academic Publishing BV, The Hague, Vol. 1, 475-481.

Buffagni A. and Furse M., 2006. Intercalibration and comparison - major results and conclusions from the STAR project. Hydrobiologia, 566, 357-364.

Buffagni A., Erba S., Birk S., Cazzola M., Feld C., Ofenböck T., Murray-Bligh J., Furse M.T., Clarke R., Hering D., Soszka H. and van de Bund W., 2005. Towards European inter-calibration for the Water Framework Directive: Procedures and examples for different river types from the E.C. project STAR. 11th STAR deliverable. STAR Contract No: EVK1-CT 2001-00089. Quaderni Ist. Ric. Acque 123, Rome (Italy), IRSA, $460 \mathrm{p}$.

Buffagni A., Erba S., Aquilano G., Armanini D.G., Beccari C., Casalegno C., Cazzola M., Demartini D., Gavazzi N., Kemp J.L., Mirolo N. and Rusconi M., 2007. Macroinvertebrati acquatici e Direttiva 2000/60/EC (WFD). IRSA-CNR Notiziario dei Metodi Analitici, 1, 116 p.

Buffagni A., Erba S., Mignuoli C., Scanu G., Sollazzo C. and Pagnotta R., 2008. Criteri per la selezione di siti di riferimento fluviali per la Direttiva 2000/60/CE. Quaderni CNR-IRSA, 1/2008, 2-22.

Cicolani B. and Di Sabatino A., 1991. Sensitivity of water mites to water pollution. In: Dusbábek F. and Bukva V. (eds.), Modern Acarology, Academia Prague and SPB Academic Publishing BV, The Hague, Vol. 1, 465-474.

Cicolani B., Miccoli F.P., Di Sabatino A., Giustini M. and Lombardo P., 2009. The value of water mites (Hydrachnidia) as indicators of biodiversity and stream ecological status: an example from Abruzzo, central Italy. In: Abstracts Book "A Cruise through Nice Waters - ASLO Aquatic Sciences Meeting". Nice, France, 25-30 January 2009, p. 51.

Cîmpean M.-D., 2010. Taxonomical and ecological study of water mite communities (Acari, Hydrachnidia) from the River Somežul Mic catchment area and their role as indicators of water quality. English summary of PhD Dissertation, Babež-Bolyai University, Cluj-Napoca, Romania, $31 \mathrm{p}$.

Dallas H.F., 2012. Ecological status assessment in mediterranean rivers: complexities and challenges in developing tools for assessing ecological status and defining reference conditions. In press at Hydrobiologia, DOI: 10.1007/s10750-012-1305-8.

Davies P.J., Wight I.A., Findlay S.J., Jonasson O.J. and Burgin S., 2010. Impact of urban development of aquatic macroinvertebrates in south eastern Australia: degradation of in-stream habitats and comparison with non urban streams. Aquat. Ecol., 44, 685-700.

Di Sabatino A., Gereke R. and Martin P., 2000. The biology and ecology of lotic water mites (Hydrachnidia). Freshw. Biol., 44, 47-62.

Di Sabatino A., Smit H., Gerecke R., Goldschmidt T., Matsumoto N. and Cicolani B., 2008. Global diversity of water mites (Acari; Hydrachnidia; Arachnida) in freshwater. Hydrobiologia, 595, 303-315.

Dohet A., Ector L., Cauchie H.M. and Hoffmann L., 2008. Identification of benthic invertebrate and diatom indicator taxa that distinguish different stream types as well as degraded from reference conditions in Luxembourg. Anim. Biol., 58, 419-472.

EU, 2000. Directive 2000/60/EC of the European Parliament and of the Council of 23 October 2000 establishing a framework for Community action in the field of water policy. Official Journal of the European Communities, L327, 1-72.

Gerecke R. and Schwoerbel J., 1991. Water quality and water mites (Acari, Actinedida) in the upper Danube Region. In: Dusbábek F. and Bukva V. (eds.), Modern Acarology, Academia, Prague and SPB Publishing BV, The Hague, Vol. 1, 483-491.

Ghetti P.F., 1997. I macroinvertebrati nel controllo della qualità di ambienti di acque correnti. Indice Biotico Esteso (IBE). Manuale di applicazione. Provincia Autonoma di Trento, Trento, Italy, 222 p.

Growns J.E., 2001. Aquatic mites as bioindicators, with an Australian example. In: Halliday R.B., Walter D.E., Proctor H.C., Norton R.A. and Calloff M.J. (eds.), Acarology, Proceedings of the 10th International Congress, CSIRO Publishing, Melbourne, 136-141.

Johnson R.K., Hering D., Furse M.T. and Verdonschot P.F.M., 2006. Indicators of ecological change: comparison of the early response of four organism groups to stress gradients. Hydrobiologia, 566, $139-152$. 
Kubošová K., Brabec K., Jarkovský J. and Syrovátka V., 2010. Selection of indicative taxa for river habitats: a case study on benthic macroinvertebrates using indicator species analysis and the random forest methods. Hydrobiologia, 651, 101-114.

Lewin I., Czerniawska-Kusza I., Szoszkiewicz K., Ławniczak A.E. and Jusik S., 2013. Biological indices applied to benthic macroinvertebrates at reference conditions of mountain streams in two ecoregions (Poland, the Slovak Republic). Hydrobiologia, 709, 183-200.

Lyche Solheim A., Feld C.K., Birk S., Phillips G., Carvalho L., Morabito G., Mischke U., Willby N., Søndergaard M., Hellsten S., Kolada A., Mjelde M., Böhmer J., Miler O., Pusch M.T., Argillier C., Jeppesen E., Lauridsen T.L. and Poikane S., 2013. Ecological status assessment of European lakes: a comparison of metrics for phytoplankton, macrophytes, benthic invertebrates and fish. Hydrobiologia, 704, 57-74.

Mandaville S.M., 2002. Benthic Macroinvertebrates in Freshwaters- Taxa Tolerance Values, Metrics, and Protocols. Soil \& Water Conservation Society of Metro Halifax (Project H-1), 128 p.

Maurer B.A. and McGill B.J., 2011. Measurement of species diversity. In: Biological Diversity - Frontiers in Measurement and Assessment, In: Magurran A. E. and McGill B.J. (eds.), Oxford University Press, Oxford, UK, pp. 55-65.

May R.M., 2011. Foreword. In: Biological Diversity - Frontiers in Measurement and Assessment, In: Magurran A.E. and McGill B.J. (eds.), Oxford University Press, Oxford, UK, pp. XV-XVII.

Miccoli F.P., Giustini M., Bruni P., Vignini P., Pescosolido M., Cicolani B. and Di Sabatino A., 2006. La biodiversità e la qualità ambientale delle sorgenti dei Monti della Laga (Parco Nazionale Gran Sasso - Laga, Appennino centrale). Atti del XXXVI Congresso della Società Italiana di Biogeografia, 93.

Mjelde M., Hellsten S. and Ecke F., 2013. A water level drawdown index for aquatic macrophytes in Nordic lakes. Hydrobiologia, 704, 141-151.

Pardo I. and Armitage P.D., 1997. Species assemblages as descriptors of mesohabitats. Hydrobiologia, 344, 111-128.

Proctor H. and Pritchard G., 1989. Neglected predators: water mites (Acari: Parasitengona: Hydrachnellae) in freshwater communities. J.N. Am. Benthol. Soc., 8, 100-111.

Quinn G.P. and Keough M.J., 2002. Experimental Design and Data Analysis for Biologists. Cambridge University Press, Cambridge, UK, 537 p.

Quiroga C.R., Vallania A. and Rosso De Ferradás B.E., 2010. Structure and distribution of Hydrachnidia (Parasitengona-Acari) in the sub-basin of the Grande River (Superior Basin of Quinto River, San Luis-Argentina). Acta Limnol. Brasil., 22, 287-294.

Resh V.H. and McElravy E.P., 1993. Contemporary quantitative approaches to biomonitoring using benthic invertebrates. In: Rosenberg D.M. and Resh V.H. (eds.), Freshwater Biomonitoring and Benthic Macroinvertebrates, Chapman and Hall, New York, 159-194.

Rossaro B., Boggero A., Lods Crozet B., Free G., Lencioni V. and Marziali L., 2011. A comparison of different biotic indices based on benthic macro-invertebrates in Italian lakes. J. Limnol., 70, $109-122$.

Schwoerbel J., 1964. Die Wassermilben (Hydrachnellae und Limnohalacaridae) als Indikatoren einer biozönotischen gliederung von Breg und Brigach sowie der obersten Donau. Arch. Hydrobiol., Suppl. 27, 1, 386-417.

Smit H. and Gerecke R., 2010. A checklist of the water mites of France (Acari: Hydrachnidia). Acarologia, 50, 21-91.

Smit H. and van der Hammen H., 1992. Water mites as indicators of natural aquatic ecosystem of the coastal dunes of the Netherlands and northwestern France. Hydrobiologia, 231, 51-64.

Smith I.M., Cook D.R. and Smith B.P., 2010. Water mites (Hydrachnidiae) and other arachnids. In: Thorp J.H. and Covich A.P. (eds.), Ecology and Classification of North American Freshwater Invertebrates, 3rd edn. Academic Press / Elsevier, Amsterdam, NL \& San Diego, CA, 485-586.

Suriano M.T., Fonseca-Gessner A.A., Roque F.O. and Froehlich C.G., 2011. Choice of macroinvertebrate metrics to evaluate stream conditions in Atlantic Forest, Brazil. Environ. Monit. Assess., 175, 87-101.

Testi A., Bisceglie S., Guidotti S. and Fanelli G., 2009. Detecting river environmental quality through plant and macroinvertebrate bioindicators in the Aniene River (central Italy). Aquat. Ecol., 43, 477-486. 
Thiébaut G., Tixier G., Guérold F. and Muller S., 2006. Comparison of different biological indices for the assessment of river quality: application to the upper River Moselle (France). Hydrobiologia, 570, 159-164.

van der Hammen H. and Smit H., 1996. The water mites (Acari: Hydrachnidia) of streams in The Netherlands: distribution and ecological aspects on a regional scale. Neth. J. Aquat. Ecol., 30, 175-185.

Viets K., 1936. Wassermilben oder Hydracarina (Hydrachnellae und Halacaridae). In: Dahl F. (ed.), Tierwelt Deutschlands. G. Fischer, Jena, 31, 10-288; 32, 289-574.

Walter C., 1924. Neue Hydracarinen aus Unterfranken. Zool. Anz., 59 (3-4), 105-108.

Washington H.G., 1984. Diversity, biotic and similarity indices - a review with special relevance to aquatic ecosystems. Water Res., 18, 653-694.

Zar J.H., 2009. Biostatistical Analysis, 5th edn. Pearson / Prentice Hall, Upper Saddle River, NJ, 944 p. 
F.P. Miccoli et al.: Knowl. Managt. Aquatic Ecosyst. (2013) 411, 08

\section{Appendix}




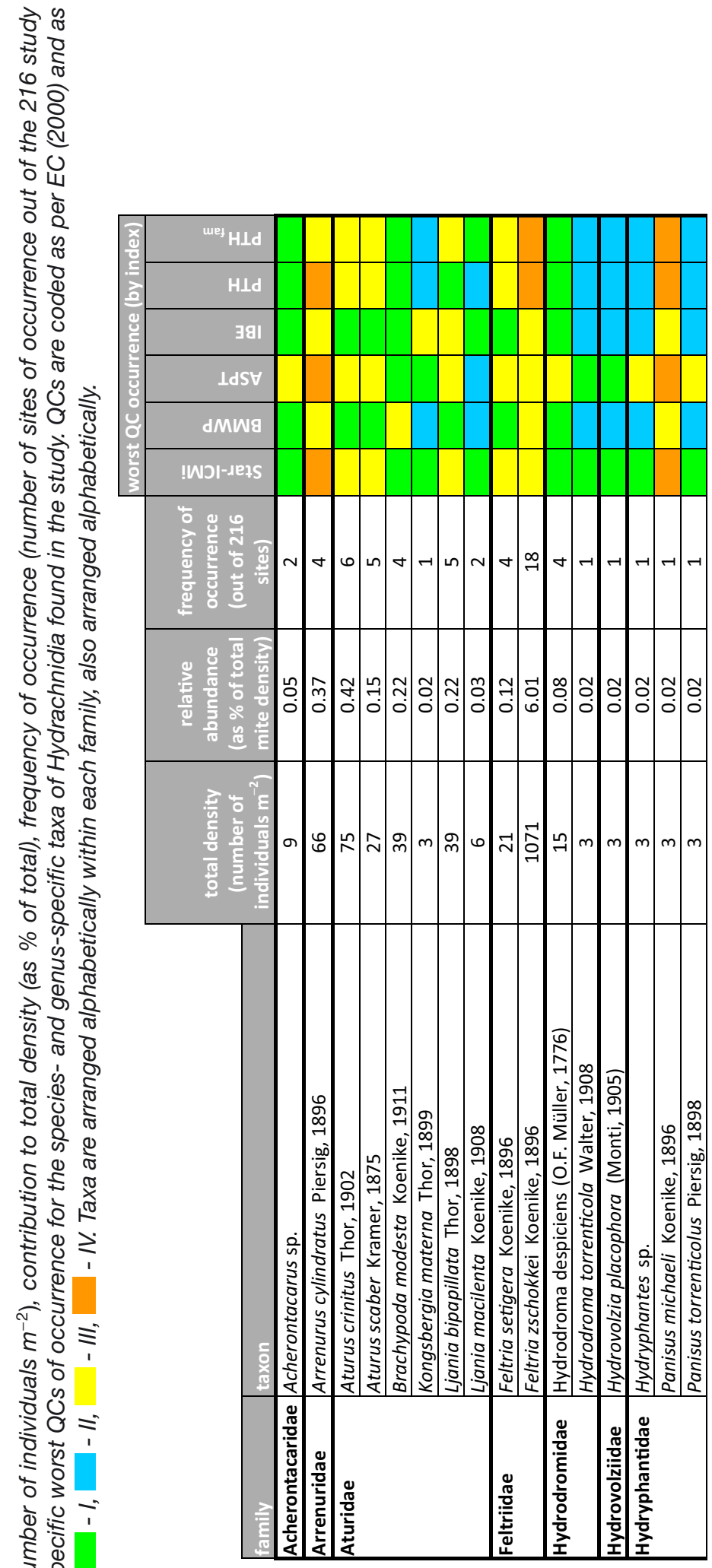

品

ट

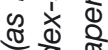

공

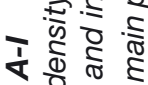

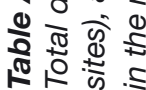




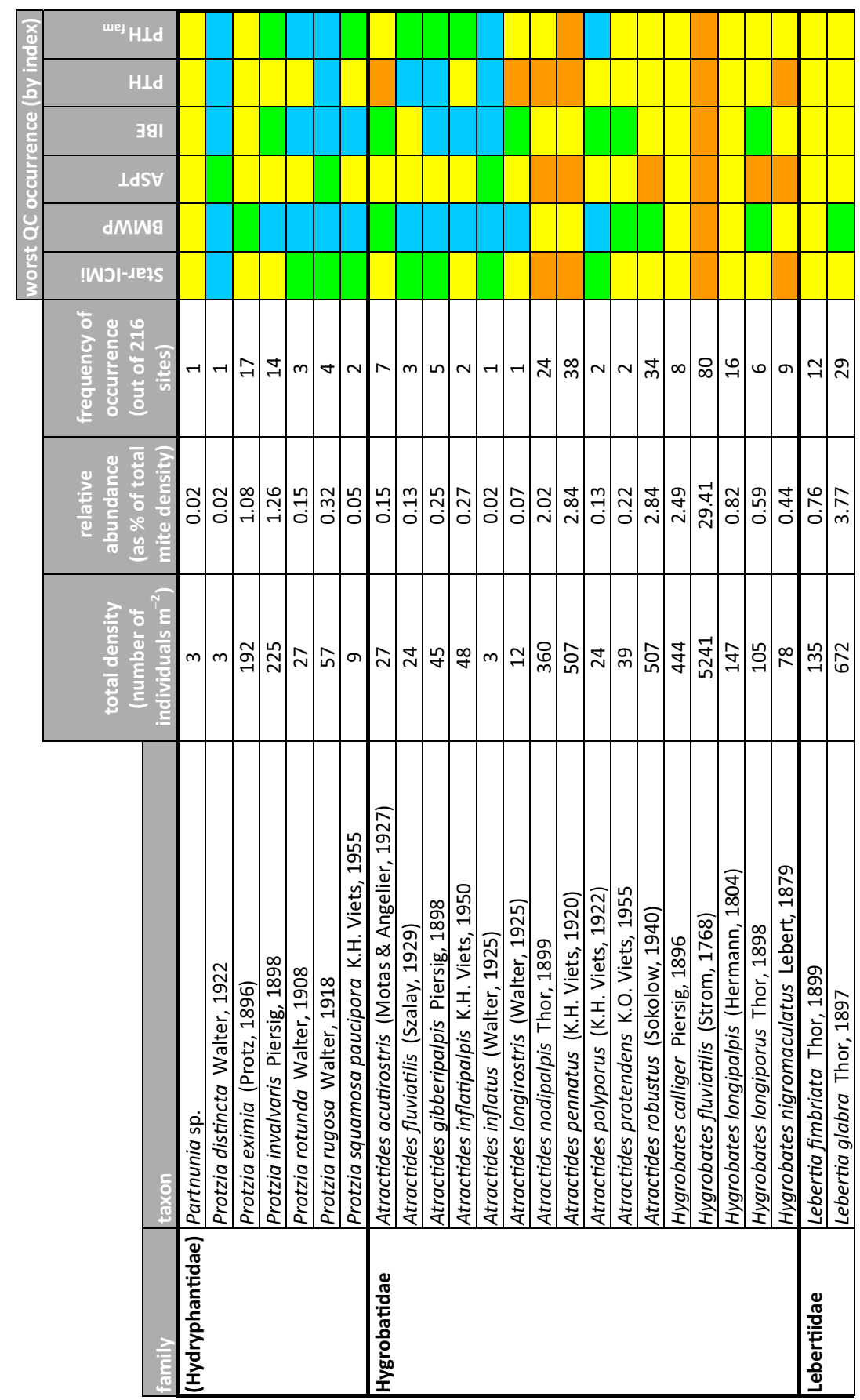

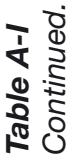




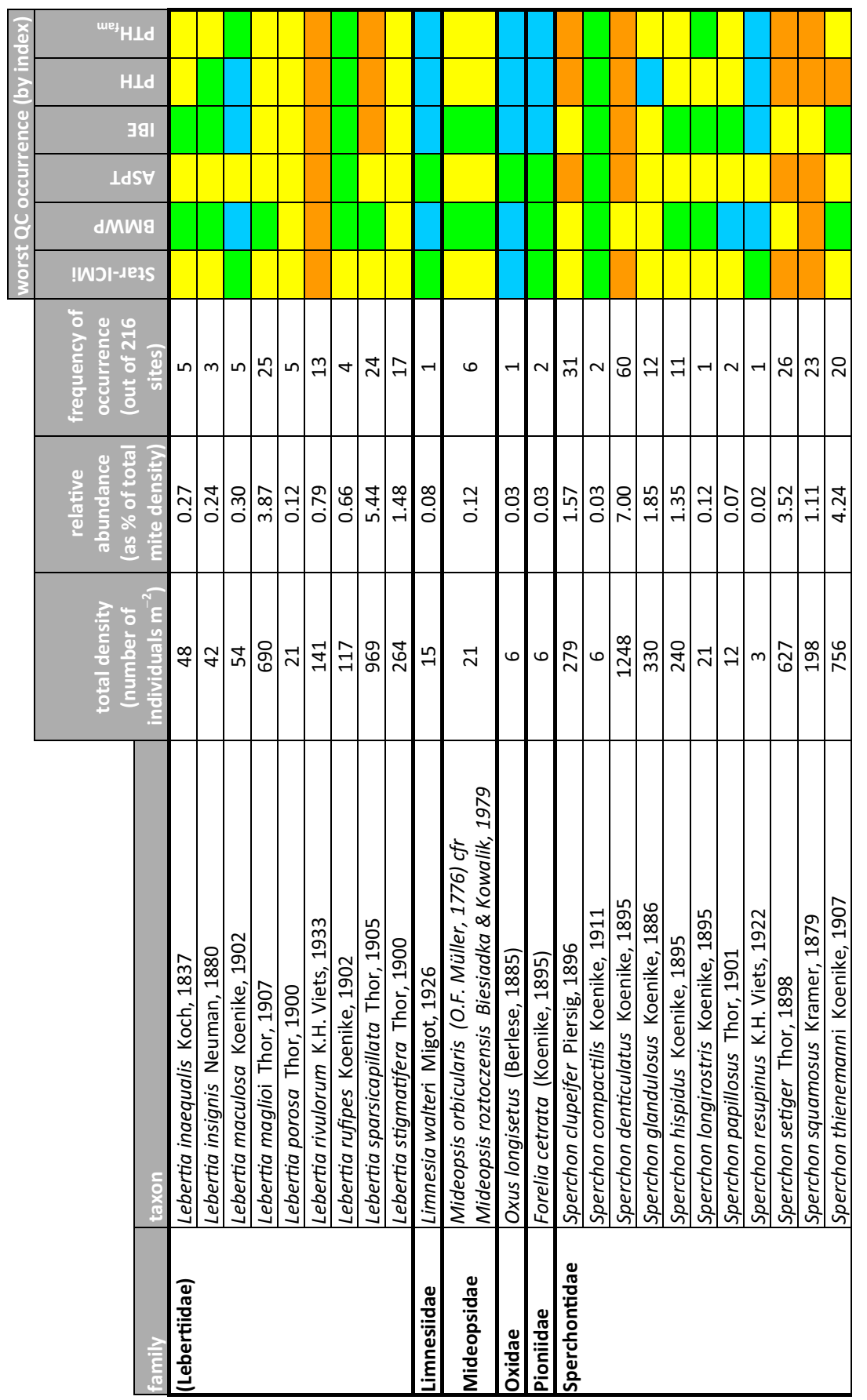

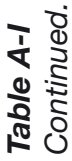




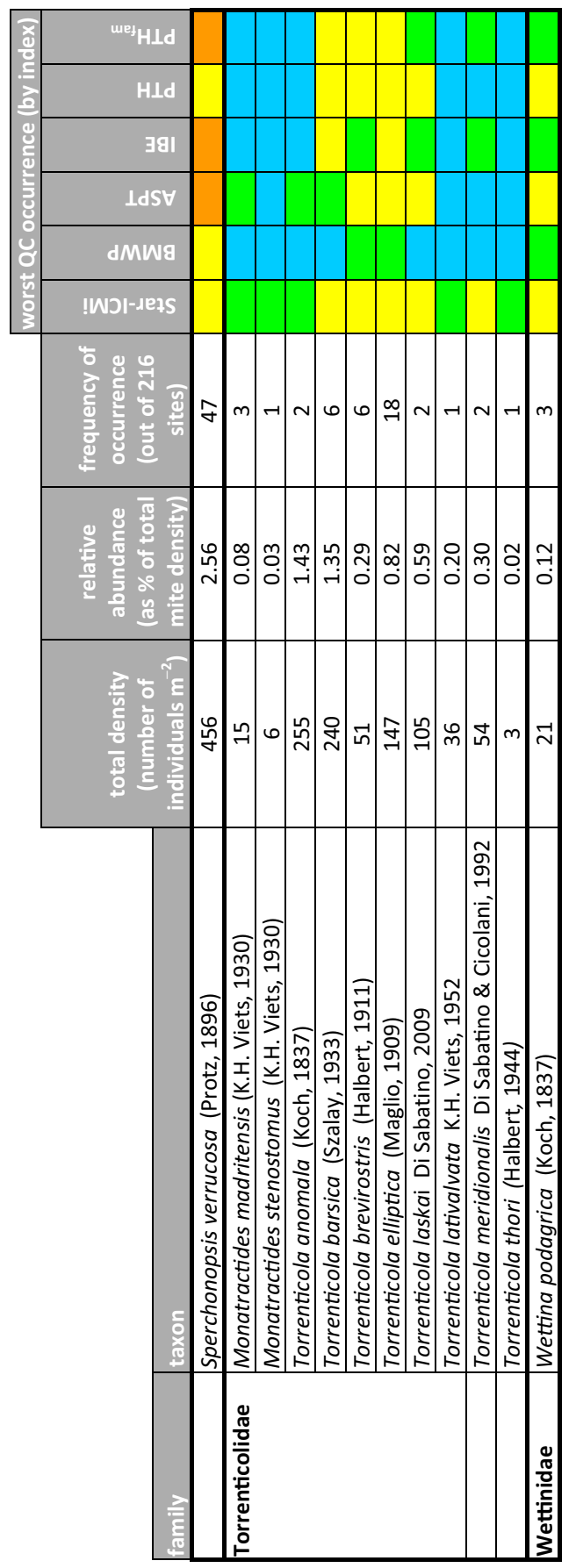

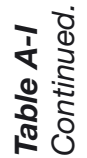




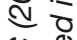

岃

ญ ญ

()

ป⿻

ㅇ․ㄴ

(1)

क

c)

ㅎํ․

क

$\stackrel{8}{5}$

$\leqslant \frac{0}{0}$

응

ปิ ส

. స

응

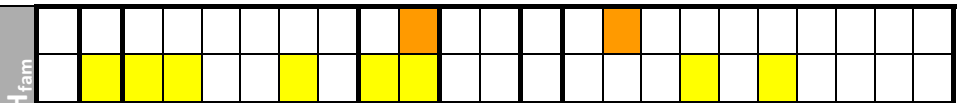

a

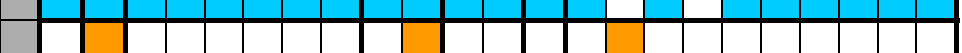

픈

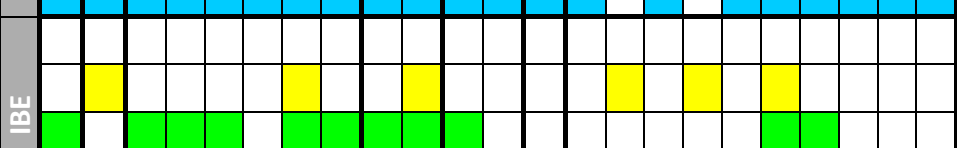

$=$
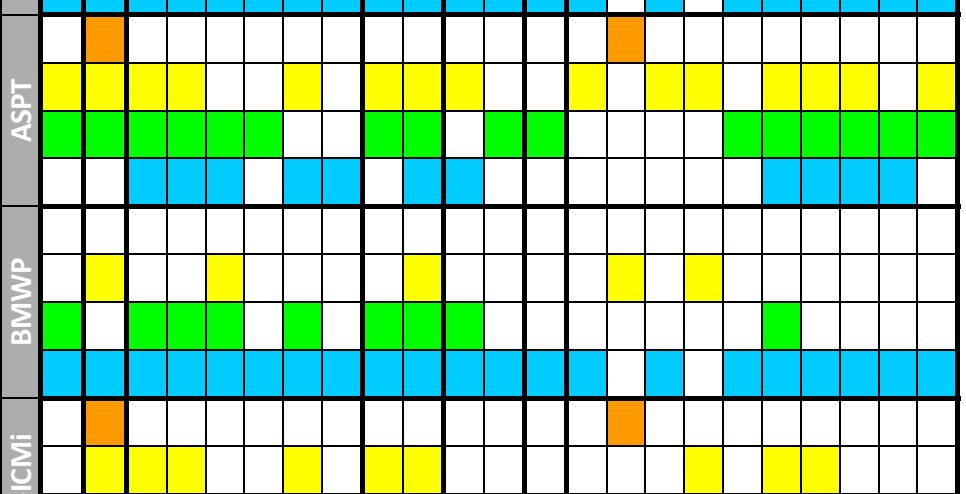

สำ

齐

○

ชิ ช

논

บ

कำ

'

(ป ปัฐ

का ช

วิ

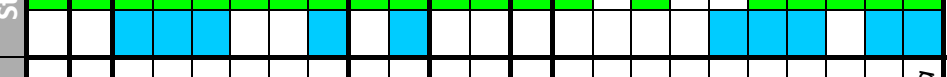

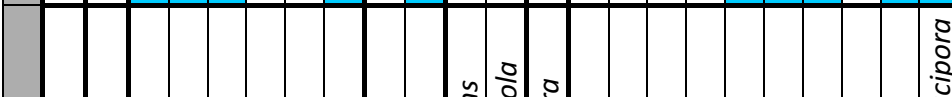

iे

은 온

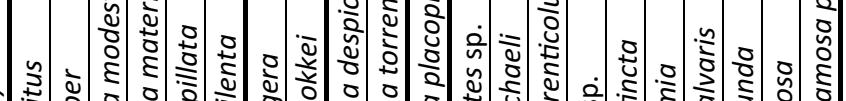

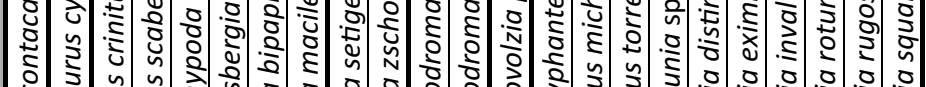

:

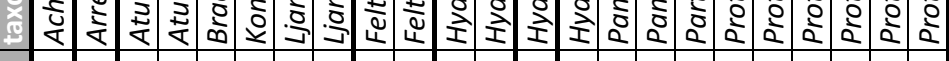

is d

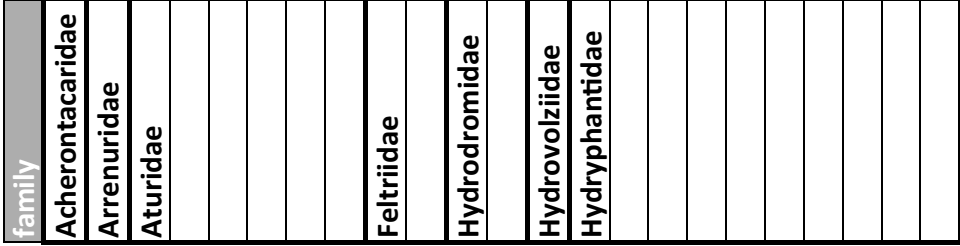

o ơ

䃞 


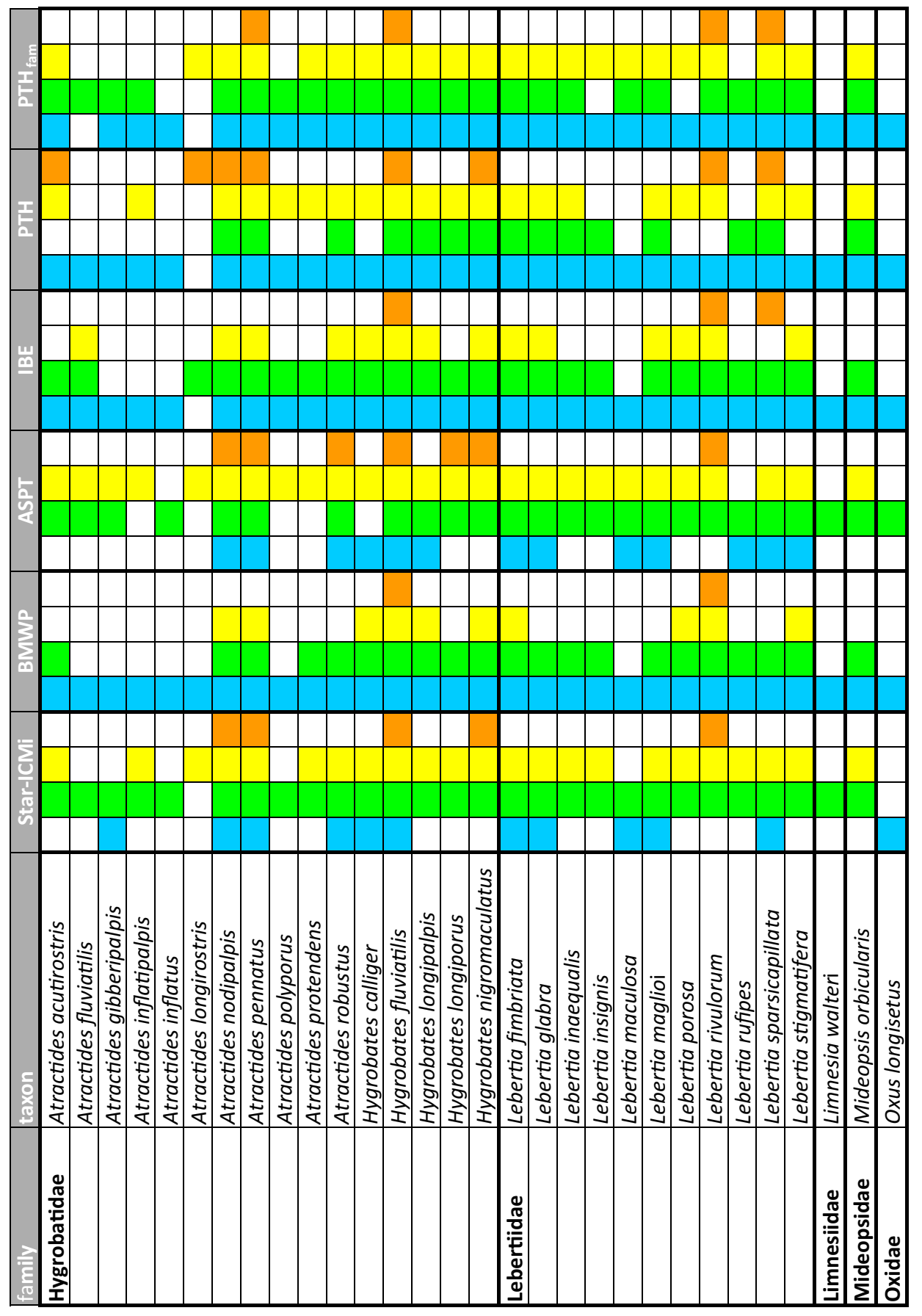

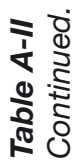




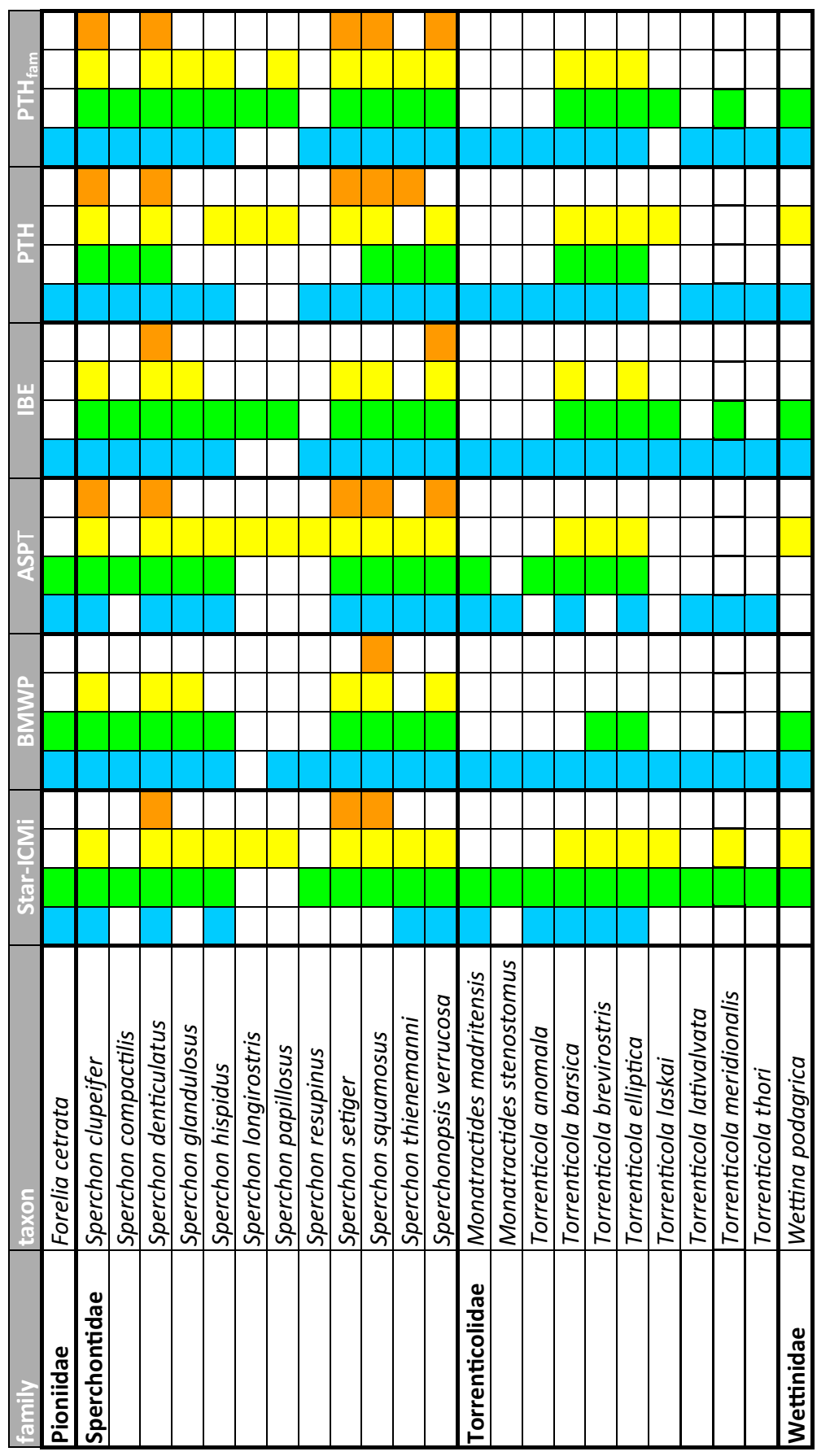

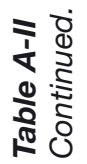




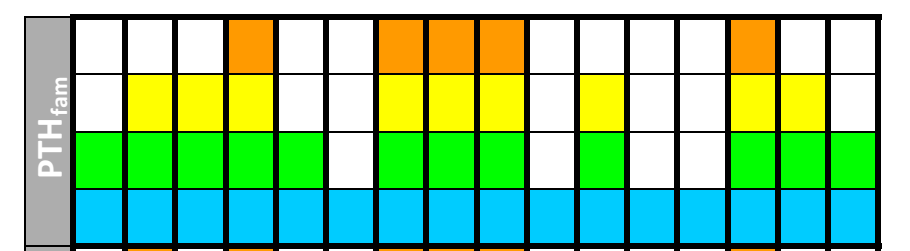

폰

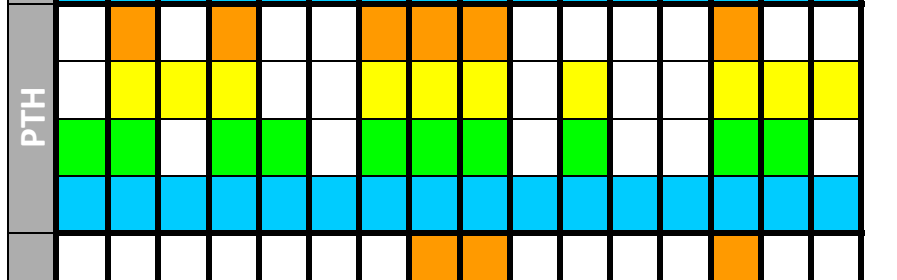

뜸

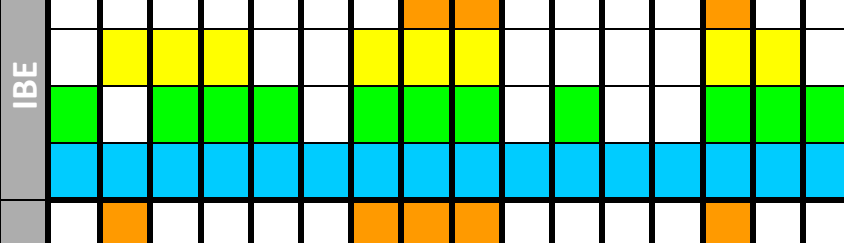

占

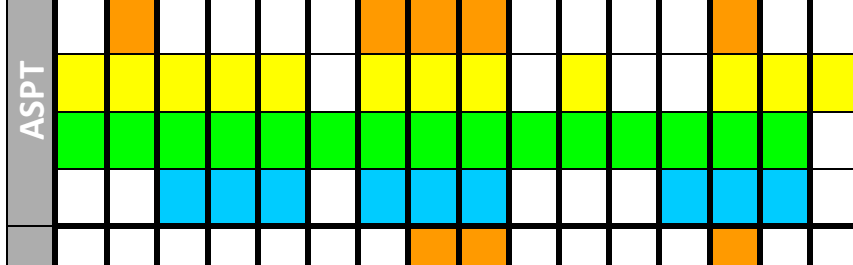

ญु

จें

क

$\stackrel{5}{5}$

?

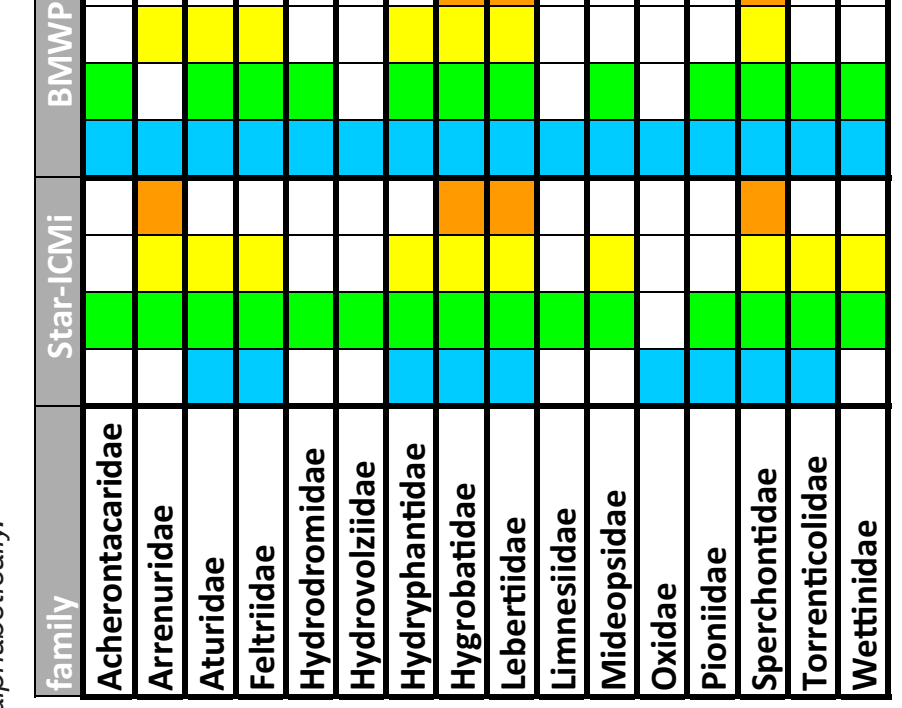

$\pi$

홍

क्ष

곤

4

क्षे

ह 농

ॠ $\frac{8}{8}$

๑) $\frac{\pi}{2}$

ఫे

c)

ठ ㅠ

$\leqslant \frac{0}{0}$

10

4 क

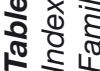

